\title{
Histones and heart failure in diabetes
}

\author{
Veera Ganesh Yerra ${ }^{1} \cdot$ Andrew Advani ${ }^{1}$
}

Received: 19 February 2018 / Revised: 12 June 2018 / Accepted: 15 June 2018 / Published online: 22 June 2018

(c) The Author(s) 2018

\begin{abstract}
Although heart failure is now accepted as being a major long-term complication of diabetes, many of the recent advances in our understanding of the pathobiology of diabetes complications have come about through the study of more traditional microvascular or macrovascular diseases. This has been the case, for example, in the evolving field of the epigenetics of diabetes complications and, in particular, the post-translational modification of histone proteins. However, histone modifications also occur in human heart failure and their perturbation also occurs in diabetic hearts. Here, we review the principal histone modifications and their enzymatic writers and erasers that have been studied to date; we discuss what is currently known about their roles in heart failure and in the diabetic heart; we draw on lessons learned from the studies of microvascular and macrovascular complications; and we speculate that therapeutically manipulating histone modifications may alter the natural history of heart failure in diabetes.
\end{abstract}

Keywords Epigenetics $\cdot$ Complications $\cdot$ Acetylation $\cdot$ Methylation $\cdot$ Cardiovascular disease $\cdot$ Post-translational modifications

\begin{tabular}{|c|c|c|c|}
\hline \multicolumn{2}{|c|}{ Abbreviations } & SAVOR & Saxagliptin Assessment of Vascular Out- \\
\hline HR & Hazard ratio & & comes Recorded in Patients with Diabetes \\
\hline $\mathrm{CI}$ & Confidence interval & & Mellitus \\
\hline USD & United States dollars & TIMI & Thrombolysis in Myocardial Infarction \\
\hline CHARM & $\begin{array}{l}\text { Candesartan in Heart failure: Assessment of } \\
\text { Reduction in Mortality and Morbidity }\end{array}$ & EXAMINE & $\begin{array}{l}\text { Examination of Cardiovascular Outcomes } \\
\text { with Alogliptin versus Standard of Care }\end{array}$ \\
\hline \multirow{4}{*}{$\begin{array}{l}\text { EF } \\
\text { HFrEF } \\
\text { HFpEF }\end{array}$} & Ejection fraction & SGLT2 & Sodium-glucose cotransporter 2 \\
\hline & Heart failure with reduced ejection fraction & CANVAS & Canagliflozin Cardiovascular Assessment \\
\hline & Heart failure with preserved ejection & & Study \\
\hline & fraction & HAT & Histone acetyltransferase \\
\hline AGE & Advanced glycation end product & HDAC & Histone deacetylase \\
\hline $\mathrm{ECG}$ & Electrocardiogram & KAT & Lysine acetyltransferase \\
\hline LVH & Left ventricular hypertrophy & KMT & Lysine methyltransferase \\
\hline $\mathrm{ACE}$ & Angiotensin converting enzyme & KDM & Lysine demethylase \\
\hline $\mathrm{ARB}$ & Angiotensin receptor blocker & KDAC & Lysine deacetylase \\
\hline $\begin{array}{l}\text { ARNI } \\
\text { GLP-1 }\end{array}$ & $\begin{array}{l}\text { Angiotensin receptor-neprilysin inhibitor } \\
\text { Glucagon-like peptide-1 }\end{array}$ & MLL & $\begin{array}{l}\text { Mixed lineage leukemia or myeloid/lym- } \\
\text { phoid leukemia }\end{array}$ \\
\hline DPP-4 & Dipeptidyl peptidase- 4 & JMJD & Jumonji domain-containing \\
\hline & & $5 \mathrm{mC}$ & 5-Methylcytosine \\
\hline & & $5 \mathrm{hmC}$ & 5-Hydroxymethylcytosine \\
\hline & & MECP2 & Methyl CpG binding protein 2 \\
\hline & & TET & Ten-eleven translocation \\
\hline \multirow[t]{2}{*}{$\triangle$} & vani & Dnmt & DNA methyltransferase \\
\hline & mh.ca & IRF1 & Interferon regulatory factor 1 \\
\hline \multirow[b]{2}{*}{ Siming I } & arch Centre for Biomedical Science and Li Ka & FOXO3 & Forkhead box O3 (FOXO3), \\
\hline & ledge Institute of St. Michael's Hospital, 6-151, & $\mathrm{pRb}$ & Retinoblastoma protein (pRB) \\
\hline
\end{tabular}




\begin{tabular}{|c|c|c|c|}
\hline STAT3 & $\begin{array}{l}\text { Signal transducer and activator of transcrip- } \\
\text { tion } 3\end{array}$ & NSD & $\begin{array}{l}\text { Nuclear receptor-binding SET domain } \\
\text { protein }\end{array}$ \\
\hline PCAF & 300/CBP-associated factor & DOT1L & DOT1-like histone-lysine methyltransferase \\
\hline GNAT & cn5-related $\mathrm{N}$-acetyltransferase & JHDM & Jumonji C domain-containing histone \\
\hline CBP & CREB-binding protein & & demethylase \\
\hline MEF2 & Iyocyte enhancer factor 2 & FBXL & F-box and leucine-rich repeat protein \\
\hline SAM & Adenosylmethionine & JARID & Jumonji/ARID domain-containing protein \\
\hline LSD & ysine-specific demethylase & RBP2 & Retinoblastoma-binding protein 2 \\
\hline FAD & lavin adenosine dinucleotide & SMCX & Smcx homolog, X chromosome \\
\hline CoREST & estin corepressor & SMCY & SMC homolog, Y chromosome \\
\hline PTIP & $\begin{array}{l}\text { Pax transcription activation domain-interact- } \\
\text { ing protein }\end{array}$ & GASC1 & $\begin{array}{l}\text { Gene amplified in squamous cell carcinoma } \\
1\end{array}$ \\
\hline TAC & Transverse aortic constriction & PHF & PHD finger protein \\
\hline CaMKII & $\begin{array}{l}\text { Calcium/calmodulin-dependent protein } \\
\text { kinase II }\end{array}$ & UTX & $\begin{array}{l}\text { Ubiquitously transcribed } \mathrm{X} \text { chromosome } \\
\text { tetratricopeptide repeat protein }\end{array}$ \\
\hline SUMO & mall ubiquitin-1 modifier & LVAD & Left ventricular a \\
\hline $\mathrm{NF}-\kappa \mathrm{B}$ & pa-light-chain-enhancer & $\begin{array}{l}\text { MHC } \\
\text { FHL1 }\end{array}$ & $\begin{array}{l}\text { Myosin heavy chain } \\
\text { Four and a half LIM domains protein } 1\end{array}$ \\
\hline DUSP5 & ificity phosphatase 5 & miR-217 & MicroRNA 217 \\
\hline TGF- $\beta 1$ & ig growth factor- $\beta 1$ & ANP & retic peptide \\
\hline MRTF-A & 1yocardin-related transcription factor-A & NOX & NADPH oxidase \\
\hline RAGE & $\begin{array}{l}\text { eceptor for advanced glycation end } \\
\text { roducts }\end{array}$ & GF1R & Insuli \\
\hline ROS & oxygen species & \multirow{3}{*}{\multicolumn{2}{|c|}{ Introduction }} \\
\hline MnSOD & ide dismutase & & \\
\hline TxnIP & Shioredoxin-inte & & \\
\hline EZH & nhancer of zeste homolog & \multirow{7}{*}{\multicolumn{2}{|c|}{$\begin{array}{l}\text { Over the past decade, there has been a growing appreciation } \\
\text { that the old dogma of diabetes complications being either } \\
\text { microvascular or macrovascular, although convenient, was, } \\
\text { in fact, wrong. Aside from the classical complications of } \\
\text { nephropathy, retinopathy, and neuropathy, and of coronary } \\
\text { artery disease, cerebrovascular disease, and peripheral vas- } \\
\text { cular disease, people with diabetes are also at increased risk } \\
\text { of certain cancers [1], cognitive impairment [2], bone frac- }\end{array}$}} \\
\hline $\mathrm{COX}-2$ & 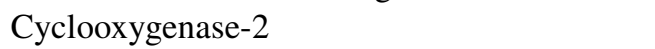 & & \\
\hline IL & terleukin & & \\
\hline IMP-9 & etalloproteinase-9 & & \\
\hline ELP3 & complex 3 & & \\
\hline MOZ & Ionocytic leukemia zinc finger protein & & \\
\hline MORF & $\begin{array}{l}\text { Monocyte leukemia zinc finger protein- } \\
\text { elated factor }\end{array}$ & & \\
\hline IBO1 & listone acetyltransferase binding to ORC-1 & \multirow{4}{*}{\multicolumn{2}{|c|}{$\begin{array}{l}\text { tures [3], and heart failure [4]. The recognition of these pre- } \\
\text { viously overlooked complications coupled with a maturing } \\
\text { understanding of the pathogenesis of classical complications } \\
\text { has led to a realization that the end-organ effects of diabetes } \\
\text { often represent a continuum rather than discrete pathological }\end{array}$}} \\
\hline LOCK & lor circodio & & \\
\hline SRC1 & ctivator-1 & & \\
\hline TIF2 & $\begin{array}{l}\text { Transcriptional mediators/intermediary fac- } \\
\text { tor } 2\end{array}$ & & \\
\hline SIRT & $\begin{array}{l}\text { Silent mating-type information regulation } 2 \\
\text { homolog }\end{array}$ & \multicolumn{2}{|c|}{$\begin{array}{l}\text { entities. The increased prevalence of heart failure in diabetes } \\
\text { exemplifies this continuum [4]. }\end{array}$} \\
\hline MYD & ET and MYND domain-containing & \multirow{9}{*}{\multicolumn{2}{|c|}{$\begin{array}{l}\text { Paralleling our evolving understanding of the continuum } \\
\text { of end-organ injury in diabetes, has been an evolving under- } \\
\text { standing of the pervasive roles that epigenetic processes may } \\
\text { play in the development of diabetes complications }[5,6] \text {. } \\
\text { The relationship between epigenetic processes and diabetes } \\
\text { complications has historically been investigated in the set- } \\
\text { ting of microvascular (reviewed in Refs. [7, 8]) or macrovas- } \\
\text { cular (reviewed in Ref. [9]) diseases, reflecting the historical } \\
\text { dichotomous classification. In contrast, the contribution of } \\
\text { epigenetic dysregulation to heart failure in diabetes has been } \\
\text { comparatively overlooked. Epigenetic processes play pivotal } \\
\text { roles in cardiac development and in the development of heart }\end{array}$}} \\
\hline SETMAR & $\begin{array}{l}\text { SET domain and mariner transposase fusion } \\
\text { protein }\end{array}$ & & \\
\hline PRDM & $\mathrm{R}$ domain & & \\
\hline SUV39H & Suppressor of variegation 3-9 homolog & & \\
\hline EHMT & $\begin{array}{l}\text { Euchromatic histone-lysine } \\
N \text {-methyltransferase }\end{array}$ & & \\
\hline GLP & G9a-like protein & & \\
\hline ESET & ERG-associated protein with SET domain & & \\
\hline SETDB & SET domain bifurcated & & \\
\hline SETD & SET domain-containing & & \\
\hline
\end{tabular}


failure in other settings [10], and it seems likely, therefore, that they play similarly pivotal roles in the development of heart failure in diabetes. The two best characterized epigenetic processes are DNA methylation and the post-translational modification of histone proteins and the epigenetic processes that, to date, have revealed themselves to be most amenable to therapeutic intervention are histone protein modifications. Here, with the goal of facilitating research in this generally understudied area, we summarize the best characterized histone modifications and their enzymatic writers and erasers; we review the evidence that histone protein modifications contribute to the development of heart failure; and we draw on lessons learned from the studies of microvascular and macrovascular diseases to consider how changes in histone proteins may affect the development of heart failure in diabetes.

\section{Heart failure in diabetes: scope of the problem}

Diabetes mellitus currently affects over 451 million people across the globe [11] and a wealth of epidemiological evidence indicates that these people are at an increased risk of developing heart failure. In the Framingham cohort, for example, the incidence of congestive heart failure was increased approximately 2.4-fold in men with diabetes and 5.3-fold in women with diabetes [12]. Likewise, in a retrospective cohort study of over 17,000 individuals with Type 2 diabetes or individuals without diabetes of similar age and sex, the incidence of congestive heart failure was more than doubled at 30.9 cases per 1000 person-years (compared to 12.4 cases per 1000 person-years for people without diabetes) [13]. Even though the incidence of heart failure increases with age, the excess risk conferred by comorbid diabetes is much higher in people of younger age, with an increased relative risk of 11-fold in individuals under the age of 45 years in comparison to 1.8-fold in individuals aged 75-84 years [13]. However, heart failure risk is not limited to individuals with Type 2 diabetes. People with Type 1 diabetes are also at increased risk. For instance, in a recent prospective case-control study of 33,402 individuals with Type 1 diabetes and 166,228 matched controls, the hazard ratio (HR) for hospitalization for heart failure was 4.69 (95\% confidence interval [CI] 3.64-6.04) [14]. For people with heart failure, the presence of comorbid diabetes increases all-cause mortality (HR 1.28 [95\% CI 1.21, 1.35]) and risk of hospitalization (HR 1.35 [1.20, 1.50]) [15]. Moreover, not only does the presence of heart failure in diabetes portend a particularly poor prognosis, but it is also vastly expensive. In one model, congestive heart failure was the most expensive incident cost in a population of 10,000 adults with diabetes, estimated at an annual expected cost of $\$ 7,320,287$ USD
[16]. In short, for people with diabetes, heart failure is prevalent, it is expensive, and it carries an, especially, poor prognosis.

People with diabetes are at increased risk of both heart failure with reduced ejection fraction (HFrEF; ejection fraction $(\mathrm{EF})<50 \%$ ) and heart failure with preserved ejection fraction (HFpEF; $\mathrm{EF} \geq 50 \%$ ). In 2012, in USA, approximately 5.8 million individuals ( $2.4 \%$ of the population) had heart failure and, in the community, approximately 50\% of heart failure cases are caused by HFpEF [17]. Approximately $40 \%$ of people with HFrEF and $45 \%$ of people with HFpEF have diabetes [18], but the outlook for people with diabetes and heart failure is poor regardless of the EF [19]. For instance, in the Candesartan in Heart failure: Assessment of Reduction in Mortality and Morbidity (CHARM) programme, both all-cause death and hospitalization were increased in people with diabetes in comparison to people without diabetes (all-cause death per 1000 patient years, diabetes 116.3 , no diabetes $72.9, p<0.001$; first hospital admissions per 1000 patient years, diabetes 473.4 , and no diabetes $327.2, p<0.001$ ) [20]. In that study, rates of cardiovascular death were 119.1 per 1000 patient years for individuals with diabetes and HFrEF and 58.6 per 1000 patient years for individuals with diabetes and HFpEF [20]. However, diabetes was associated with a greater risk of cardiovascular death or hospitalization for heart failure in people with HFpEF than it was in people with a reduced EF (HFpEF and diabetes, HR 2.0 [1.70-2.36]; HFrEF and diabetes, HR 1.60 [1.44-1.77]; interaction test, $p=0.0009$ ) [20].

\section{Causes of heart failure in diabetes}

In 1972, investigators reported post-mortem findings of heart failure in four individuals with diabetes but without coronary artery disease [21]. This led to the coining of the term "diabetic cardiomyopathy" used to describe myocardial dysfunction in a person with diabetes, but in the absence of hypertension or coronary artery disease [22]. However, the term itself remains imperfectly defined and the extent to which elevated blood glucose levels alone can cause myocardial dysfunction remains controversial. For example, one study that combined functional, biochemical, and morphological techniques failed to identify evidence of myocardial dysfunction in 185 persons with Type 1 diabetes, with a mean duration of diabetes of over 20 years but without coronary artery disease or hypertension [23]. Nonetheless, the increased prevalence of heart failure in diabetes is undisputed and just as the term "diabetic kidney disease" is now favored over "diabetic nephropathy", so "heart failure in diabetes" may be preferred over "diabetic cardiomyopathy", attesting to the multifactorial nature of the condition and the common coexistence of 
predisposing comorbidities. With respect to these predisposing comorbidities, the prevalences of both coronary artery disease [24] and hypertension [25] are increased in people with diabetes and diabetes exacerbates all forms of cardiovascular disease [26]. At a molecular level, hyperglycemia and accompanying formation of advanced glycation end products (AGEs), endothelial dysfunction, impaired calcium homeostasis, oxidative stress, inflammation, abnormalities in glucose and fatty acid utilization, autonomic dysfunction, myocardial fibrosis, and small vessel disease act in concert to impair myocardial function in diabetes (reviewed in Refs. [27-29]). This manifests as left ventricular hypertrophy (LVH) and adverse remodeling, ultimately impairing systolic and/or diastolic function [26] (Fig. 1). Indeed, electrocardiogram (ECG) or echocardiogram evidence of LVH signifies a high risk for the development of heart failure [30] and in the Look AHEAD trial approximately $5 \%$ of overweight or obese individuals with Type 2 diabetes had ECG evidence of LVH [31].

\section{Heart failure in diabetes and its relationship to current treatments}

\section{Heart failure treatments}

Conventionally, the treatment of heart failure in people with diabetes has been the same as for people without diabetes. Therapy for heart failure includes the use of renin-angiotensin system blockers such as angiotensin converting enzyme (ACE) inhibitors, angiotensin receptor blockers (ARBs), or an angiotensin receptor-neprilysin inhibitor (ARNI), aldosterone receptor antagonists, $\beta$-blockers, diuretics, combination of hydralazine and isosorbide dinitrate, ivabradine, and digoxin if indicated and device therapy with an implantable cardioverter defibrillator or cardiac resynchronization therapy where appropriate $[32,33]$. The evidence supporting the use of these agents derives from the studies of individuals with HFrEF, and unfortunately, similar evidence of their benefit in individuals with HFpEF is lacking [32, 34].
Fig. 1 Cellular processes affected by diabetes and its comorbidities that affect cardiac cell function and that can predispose to heart failure development

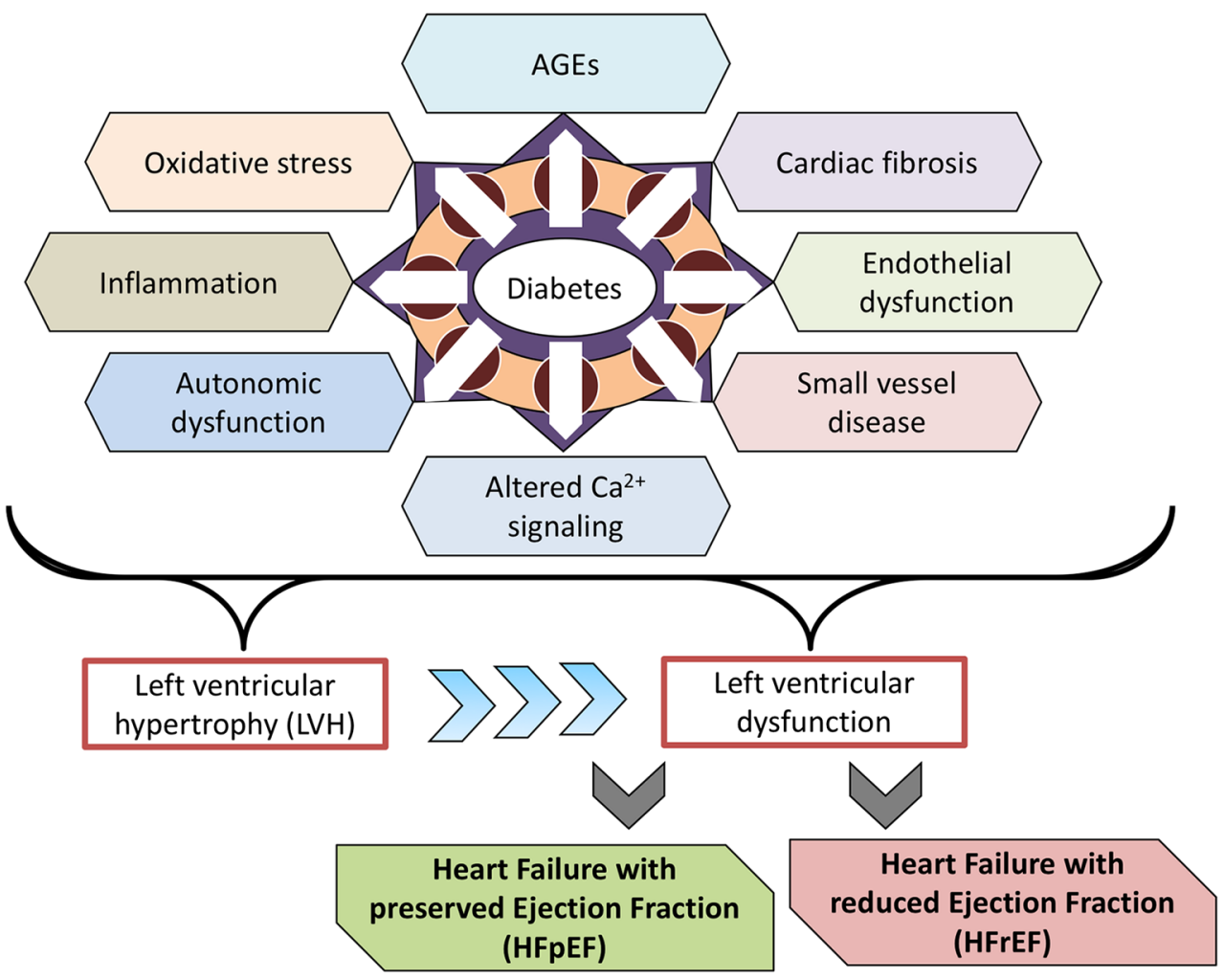




\section{Anti-hyperglycemic agents and their relationship to heart failure in diabetes}

The relationship between heart failure risk and agents used to lower blood glucose levels in people with Type 2 diabetes has recently been reviewed [26]. Briefly, blood glucoselowering therapies may worsen heart failure, have neutral effects, or, in some cases, actually improve outcomes in patients. For instance, the thiazolidinediones, rosiglitazone, and pioglitazone have both been associated with an increased risk of admission to hospital with heart failure [35, 36]. With respect to heart failure outcomes, incretin-based therapies [i.e., glucagon-like peptide-1 (GLP-1) receptor agonists or dipeptidyl peptidase-4 (DPP-4) inhibitors] may be largely neutral [37-41], although the DPP-4 inhibitor, saxagliptin, was associated with an unexpected increase in the risk of hospitalization for heart failure in the Saxagliptin Assessment of Vascular Outcomes Recorded in Patients with Diabetes Mellitus (SAVOR)-Thrombolysis in Myocardial Infarction (TIMI) 53 trial (HR 1.27, [95\% CI 1.07-1.51]) [42]. Similarly, in the Examination of Cardiovascular Outcomes with Alogliptin versus Standard of Care (EXAMINE) trial, the number of participants hospitalized for heart failure was numerically greater, albeit non-significantly, with the DPP-4 inhibitor alogliptin than with placebo (3.1 vs. $2.9 \%$; HR 1.0 [95\% CI 0.79-1.46]) [43]. Unfortunately, for older blood glucose-lowering agents (i.e., metformin, sulphonylureas, and insulin), there are insufficient data to draw robust conclusions as to safety, benefit, or harm. This is because these agents were in clinical use for many years prior to the 2008 U.S. Food and Drug Administration Guidance for Industry that mandated the demonstration of the absence of cardiovascular harm for anti-hyperglycemic agents used in the treatment of Type 2 diabetes [44].

In 2015, the results of the EMPA-REG OUTCOME trial surprised many in the diabetes clinical care and research communities by demonstrating a significant reduction in cardiovascular events in people with Type 2 diabetes at high cardiovascular risk treated with the sodium-glucose cotransporter 2 (SGLT2) inhibitor, empagliflozin [45]. In that study, treatment with empagliflozin was associated with a significant reduction in the primary outcome of major adverse cardiovascular events (HR 0.86 [95.02\% CI 0.74-0.99], $p=0.04$ for superiority), a $38 \%$ relative risk reduction for death from cardiovascular causes, a $32 \%$ relative risk reduction for death from any cause, and a 35\% risk reduction for hospitalization for heart failure (2.7 vs. 4.1\%) [45]. In the Canagliflozin Cardiovascular Assessment Study (CANVAS) Program, hospitalization for heart failure was similarly reduced with the SGLT2 inhibitor canagliflozin (HR 0.67 [95\% CI 0.52-0.87]), although there was an increased risk of amputation (HR 1.97 [95\% CI 1.41-2.75]) [46]. In both EMPA-REG OUTCOME [47] and CANVAS [46], over 85\% of participants had no prior history of heart failure, and thus, the beneficial effects of SGLT2 inhibition may be viewed as being those of heart failure prevention rather than necessarily heart failure treatment. Indeed, there is a relative paucity of data on the efficacy of SGLT2 inhibitors in patients with established heart failure, with or without diabetes, and there is a similar paucity of data as to whether SGLT2 inhibitors are equally effective in patients with $\mathrm{HFpEF}$ and HFrEF [26]. Furthermore, even in the impressive EMPAREG OUTCOME study, treatment with empagliflozin, on top of standard-of-care, and thus arguably representing current best practice, did not negate heart failure, only reducing it, hospitalization for heart failure still occurring at a rate of 9.4/1000 patient years [45]. As the global prevalence of diabetes increases over the coming years (expected to exceed 693 million people by 2045 [11]), there is thus a pressing need to explore innovative new treatment opportunities. One such opportunity may be to exploit the post-translational modification of histone proteins and the effects that these changes can have on gene transcription and cellular (dys) function.

\section{Histone protein post-translational modifications and the enzymes that control them}

Histones are the basic protein building blocks of chromatin and, together with DNA, they make up the fundamental unit of chromatin, the nucleosome core particle. A nucleosome core particle consists of approximately 146 bp of DNA wrapped nearly twice around a histone octamer which itself is made up of two copies each of the four core histone proteins $\mathrm{H} 2 \mathrm{~A}, \mathrm{H} 2 \mathrm{~B}, \mathrm{H} 3$, and $\mathrm{H} 4$ (Fig. 2) [48]. Nucleosomes are joined together by stretches of linker DNA. H1 linker histones, whilst not being part of the nucleosome core particle, bind linker DNA at the entry and exit sites of the nucleosome and help to stabilize the whole complex [49]. In comparison to the core histone proteins, the function of linker histones has been relatively less well characterized [50]. The packaging of DNA into nucleosomes and hence chromatin enables it to exist in a very condensed fashion, essentially providing a means whereby the approximate $2 \mathrm{~m}$ length of a DNA strand can fit inside a eukaryotic nucleus that is typically less than $10 \mu \mathrm{m}$ in diameter. This packaging is important for how changes in histone proteins can influence the expression of nearby genes. Histone proteins have long, protruding amino tails that are susceptible to a range of post-translational modifications and these modifications can facilitate gene activation or repression. Histone protein post-translational modifications include acetylation, methylation, phosphorylation, ubiquitination, SUMOylation, 


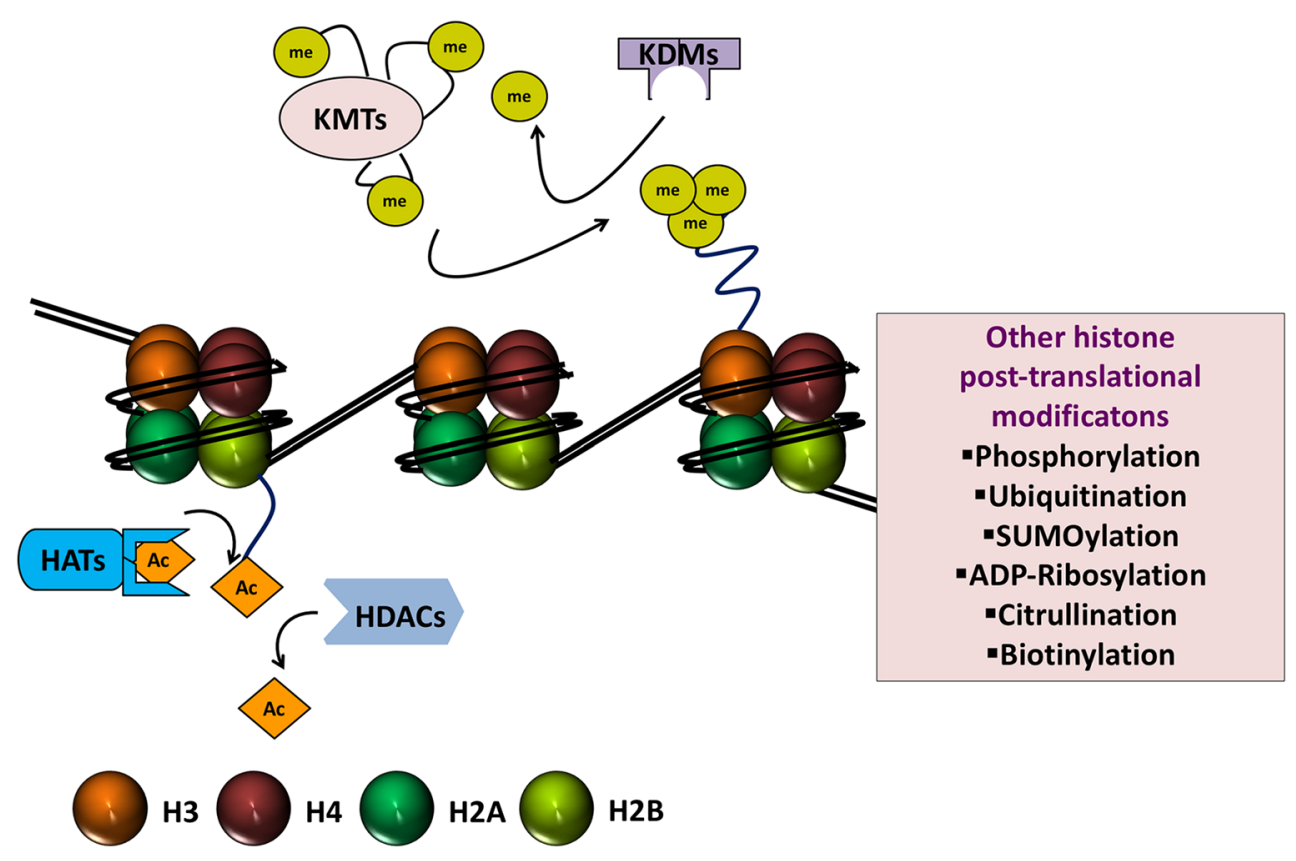

Fig. 2 Nucleosome core particle, histone proteins, and histone writers and erasers. The nucleosome is made up of approximately $146 \mathrm{bp}$ of DNA coiled nearly twice around an octamer of histone proteins, made up of two copies each of histone $\mathrm{H} 2 \mathrm{~A}$, histone $2 \mathrm{~B}$, histone $\mathrm{H} 3$, and histone $\mathrm{H} 4$. The protruding amino tails of histone proteins can undergo post-translational modifications that affect the expression of genes in close proximity. Illustrated are the major histone post-translational modifications that have been studied in the context of heart

ADP ribosylation, citrullination, and biotinylation [51]. By far and away, the best characterized of these modifications are histone-lysine acetylation and deacetylation and histone-lysine methylation and demethylation, and thus, these modifications are the focus of the current treatise.

\section{The nomenclature of histone writers and erasers}

The acetylation or deacetylation of lysine residues on histone proteins is regulated by two opposing groups of enzymes: histone acetyltransferases (HATs) and histone deacetylases (HDACs), and the methylation or demethylation of lysine residues on histone proteins is regulated by histone methyltransferases and lysine demethylases. The discovery of these enzymes resulted in nomenclature systems that are somewhat non-coherent and also inconsistent between species, and in an effort to rectify this situation, in 2007, scientists proposed a new nomenclature [52]. Thus, HATs are also referred to as KATs, lysine methyltransferases as KMTs, and lysine demethylases as KDMs, where $\mathrm{K}=$ lysine [52]. At the time of the new nomenclature, the authors did not propose renaming the HDAC family as they felt that this classification was failure and diabetes (i.e., acetylation and deacetylation and methylation and demethylation), along with their enzymatic writers and erasers, histone acetyltransferases (HATs or KATs, where $\mathrm{K}=$ lysine), histone deacetylases (HDACs), histone methyltransferases (HMTs or KMTs), and lysine demethylases (KDMs). Other post-translational modifications that can affect histones and consequently gene expression but that have been comparatively less well studied in heart failure and diabetes are shown in the boxed area

coherent enough [52]. However, authors will occasionally refer to HDACs as KDACs (e.g., [53]), recognizing that histones are not the only substrates of many lysine residuemodifying enzymes.

\section{Mechanisms through which histone modifiers and histone modifications facilitate gene activation or repression}

Histone modifications can influence gene transcription by several mechanisms that can be broadly classified into two categories: (1) by altering chromatin compaction (a direct effect); and (2) by influencing the recruitment of effector complexes (indirect effects) [51, 54, 55]. Histone modifications can affect chromatin compaction by altering the electrostatic charge relationship between histone proteins and DNA. This can be the case for histone acetylation or phosphorylation. For instance, by neutralizing the charge on lysine residues, acetylation can weaken the association between positively charged histone proteins and negatively charged DNA, thus improving the accessibility of protein machinery to target sites of DNA. The indirect effects of histone protein modifications on effector recruitment and retention are, however, more pervasive in terms of their 
influence on gene transcription. These indirect effects influence the actions of chromatin-modifying enzymes, transcription factors, and other histone protein modifiers and modifications. For example, histone modifications can facilitate the recruitment or regulate the efficiency of ATP-dependent chromatin remodeling enzymes (e.g., SWitch/Sucrose NonFermentable (SWI/SNF) [56]) that enhance the accessibility of nucleosomal DNA, playing an important role in the regulation of transcription by RNA polymerase II [57]. The enzymes responsible for histone protein post-translational modification are often co-recruited to their target sites in protein complexes together with transcription factors [58], and histone modifications can influence the recruitment of transcription factors at epigenetically distinct transcriptional start sites, proximal promoter regions, and distal enhancers [59-61]. Alternatively, by blocking the access of remodeling complexes to chromatin, certain histone protein modifications limit gene transcription [54]. They can also influence the recruitment of other histone modifiers, and consequently, the formation of other histone modifications [62]. For example, the HAT Gcn 5 can acetylate lysine residue 14 on histone H3 (H3K14) more effectively when serine residue 10 on histone protein $\mathrm{H} 3$ (H3Ser10) is phosphorylated [63]. Finally, certain histone modifications are mutually exclusive. For example, H3K4 methylation generally marks actively transcribed genes and is associated with $\mathrm{H} 3 \mathrm{~K} 9$ hypomethylation. This arrangement may be mediated by the physical and functional association of the H3K4 methyltransferase mixed lineage leukemia or myeloid/lymphoid leukemia 2 (MLL2) and the $\mathrm{H} 3 \mathrm{~K} 9$ demethylase Jumonji domain-containing 2B (JMJD2B) [64].

Histone protein modifications also function in tandem with the other major category of epigenetic processes, DNA methylation. Classically, methylation of DNA has been studied in the context of its occurrence at the 5-position of cytosine residues (referred to as 5-methylcytosine, or $5 \mathrm{mC}$ ) most commonly located within regions of DNA known as CpG islands [65, 66]. These are regions of DNA arbitrarily greater than $200 \mathrm{bp}$ in length that contain phosphodiester-linked cytosine and guanine residues occurring at a frequency of more than 50\%. Methylation of $\mathrm{CpG}$ islands at transcriptional start sites serves as a recognition point for reader proteins, such as methyl $\mathrm{CpG}$ binding protein 2 (MECP2), which block gene transcription [67]. Accordingly, in this context, DNA methylation is generally considered to facilitate transcriptional repression. However, DNA methylation can also occur away from transcriptional start sites, including in gene bodies, and at these sites, DNA methylation may not be associated with gene repression but may alternatively be involved in gene activation (by the preclusion of repressor binding sites) or in alternative splicing [68]. More recently, it has been recognized that gene transcription may also be regulated by the oxidative formation of 5-hydroxymethylcytosine (5hmC, DNA hydroxymethylation), a process that is regulated by the ten-eleven translocation (TET) family of $5 \mathrm{mC}$ dioxygenases, which is commonly (although not exclusively) associated with transcriptional activation [69-73]. Histone protein modifications and DNA methylation are commonly interrelated, one epigenetic mark influencing the generation of the other and vice versa [74]. This bidirectional relationship can be mediated by direct interactions between histone modifications and DNA methylating enzymes or between sites of DNA methylation and histone-modifying enzymes. For example, the DNA methyltransferase Dnmt3a possesses an interacting domain that links DNA methylation to unmethylated $\mathrm{H} 3 \mathrm{~K} 4$, whereas the H3K4 methyltransferase MLL1 contains a CpG-interacting domain that could link H3K4 methylation to unmethylated DNA [75].

Aside from their effects on histone proteins, many ostensibly histone-modifying enzymes can also modify non-histone proteins, especially transcription factors. These modifications can influence gene expression by affecting transcription factor stability and function. This is the case for both lysine (de)acetylating and lysine (de)methylating enzymes. For example, the enzyme SET7/9 methylates histone proteins, transcription factors, and other epigenetic regulators. In its role as a histone methyltransferase, SET7/9 monomethylates H3K4 [76]. However, several transcription factors have also been found to be substrates for SET7/9 (e.g., p53, E2F1, interferon regulatory factor 1 (IRF1), forkhead box O3 (FOXO3), p65, retinoblastoma protein (pRb), and signal transducer and activator of transcription 3 (STAT3), amongst others) [77, 78]. Furthermore, SET7/9 also methylates other enzymes that can exert their own epigenetic effects, including Dnmt1 [79] and the HAT, p300/CBP-associated factor (PCAF) [80], affecting their enzymatic activities. Thus, when interpreting the effects of histone-modifying enzymes, one should remain cognizant that these effects may be both chromatin-dependent and chromatin-independent.

In summary, histone-modifying enzymes or histone modifications rarely, if ever, function in isolation to regulate gene transcription. Rather, a conceptual framework is beginning to emerge whereby functional genomic regions are tagged by specific histone marks that support the transcriptional response to stimuli, histone modifications functioning synergistically with each other, with other epigenetic regulators and with canonical transcription factors.

\section{Histone acetylation}

Utilizing acetyl CoA as a cofactor, HATs catalyze the transfer of acetyl groups to the $\varepsilon$-amino group of the lysine side chain of histone proteins, which neutralizes the histone protein's positive charge and weakens the interaction between histones and DNA. This causes chromatin to adopt a more 
open conformation that favors transcriptional activation. By removing acetyl groups from lysine residues, HDACs restore the positive charge of histone tails leading to chromatin condensation which should favor transcriptional repression [81]. In reality, however, the situation is more complex than this. For instance, histone acetylation may also serve as a recognition point for bromodomains [55, 82], which are modules of approximately 110 amino acids in length commonly present in many proteins that associate with chromatin [82].

HATs can be grouped into five subfamilies: the Gcn5related $\mathrm{N}$-acetyltransferase (GNAT) superfamily, MYST [named after its first four members: MOZ, Ybf2 (Sas3), Sas2, and Tip60], p300/CBP (CREB-binding protein), transcription factors, and nuclear receptor cofactors (Table 1). There are at least 18 different HDAC enzymes, which are subdivided phylogenetically into four classes. Classes I, II, and IV are zinc-dependent histone deacetylases and comprise: Class I (HDACs 1, 2, 3 and 8), Class IIa (HDACs 4, 5, 7 and 9), Class IIb (HDACs 6 and 10), and Class IV (HDAC11). Class III HDACs, the sirtuins, are $\mathrm{NAD}^{+}$-dependent and, in mammals, comprise at least seven members (SIRTs 1-7) (Table 2). Both HATs and HDACs are recruited to target promoter regions as parts of large protein complexes and both classes of enzymes exhibit poor specificity for the lysine residues that they acetylate or deacetylate [83].
Numerous proteins, other than histones, can be lysine acetylated or deacetylated by HATs and HDACs and, as already discussed, the terms HATs and HDACs are somewhat of misnomers. For instance, one study seeking to gauge the extent of the lysine acetylome identified 1750 acetylated proteins in MV4-11 cells [84], whereas the HDAC, HDAC6 are localized almost exclusively in the cytosol [85]. It is, perhaps, unsurprising then that many of the studies linking lysine acetylation to either cardiac development or the (patho) physiological response to cardiac stress have demonstrated that the pivotal actions of HATs or HDACs are mediated by their acetylation or deacetylation of non-histone proteins. For instance, mutation of the Class II HDACs, HDAC5, and HDAC9 results in embryonic or perinatal lethality with variable penetrance accompanied by ventricular septal defects and a thin-walled myocardium, possibly due to superactivation of the transcription factor, myocyte enhancer factor 2 (MEF2), which is known to interact with Class II HDACs and control cardiomyocyte differentiation [86, 87]. However, the specific acetylation of histone proteins is also important to cardiac development and function. For example, the master cardiac transcription factor, GATA4, which is required for both cardiac development [88, 89] and in the adult heart [90], drives gene expression by stimulating histone H3 lysine 27 acetylation (H3K27ac) [91].
Table 1 Histone acetyltransferase (HAT) subfamilies and enzymes in humans

\begin{tabular}{llll}
\hline Subfamily & Enzyme examples & $\begin{array}{l}\text { Alternative } \\
\text { nomenclature }\end{array}$ & Histone residues acetylated \\
\hline GNAT superfamily & GCN5 & KAT2 & H3 (H4, H2B) \\
& PCAF & KAT2B & H3, H4 \\
& HAT1 & KAT1 & H2AK5, H3, H4 \\
& ELP3 & KAT9 & H3 \\
MYST & Tip60 & KAT5 & H2A, H3, H4 \\
& MOZ & KAT6A & H3, H4 \\
& MORF & KAT6B & H2A, H3, H4 \\
& HBO1 & KAT7 & H3, H4 \\
p300/CBP & MYST1 & KAT8 & H4 \\
& p300 & KAT3B & H2A, H2B, H3, H4 \\
Transcription factors & CBP & KAT3A & H2A, H2B, H3, H4 \\
& TAF 250 & & H3, H4 \\
& TFIIC90 & KAT12 & H2A, H3, H4 \\
& CLOCK & KAT13D & H3, H4 \\
Nuclear receptor cofactors & SRC1 & KAT13A & H3, H4 \\
& ACTR & KAT13B & H3, H4 \\
& TIF2 & KAT13C & H3, H4 \\
\hline
\end{tabular}

Adapted from Refs. [52, 166, 167]

GNAT Gcn5-related $N$-acetyltransferases, KAT K-acetyltransferase, PCAF p300/CBP-associated factor, $H A T 1$ histone acetyltransferase 1, ELP3 elongator protein complex 3, MOZ monocytic leukemia zinc finger protein, $M O R F$ monocyte leukemia zinc finger protein-related factor, $H B O 1$ histone acetyltransferase binding to ORC-1, CBP CREB-binding protein, $C L O C K$ clock circadian regulator, SRC1 steroid receptor coactivator-1, TIF2 transcriptional mediators/intermediary factor 2 
Table 2 Classes of histone deacetylase enzymes in humans

\begin{tabular}{ll}
\hline Class & Enzymes \\
\hline Class I & HDAC1, HDAC2, HDAC3, HDAC8 \\
Class IIa & HDAC4, HDAC5, HDAC7, HDAC9 \\
Class IIb & HDAC6, HDAC10 \\
Class III & SIRT1, SIRT2, SIRT3, SIRT4, \\
& SIRT5, SIRT6, SIRT7 \\
Class IV & HDAC11 \\
\hline
\end{tabular}

Adapted from Ref. [168]

$H D A C$ histone deacetylase, SIRT silent mating-type information regulation 2 homolog

\section{Histone methylation}

Lysine residues can be acetylated or methylated, but they cannot be both. In contrast to histone acetylation, histone methylating (and demethylating) enzymes can be remarkably specific. Histone protein methylation is catalyzed by histone methyltransferase enzymes and can occur on either lysine or arginine residues. Over 30 human proteins have histone methyltransferase activity. Amongst the histone methyltransferase family, the PRMT enzymes catalyze the methylation of arginine residues, whereas the SET family of proteins catalyze the methylation of lysine residues [92]. Lysine residues may be mono- (me1), di- (me2), or tri- (me3) methylated, whereas arginine residues may be either mono- or di- methylated [93]. Histone-lysine methyltransferases
(KMTs) catalyze the transfer of a methyl group from $s$-adenosylmethionine (SAM) to $\varepsilon$-amino groups on lysine residues of histone tails [94], and RMTs catalyze the transfer of methyl groups from SAM to $\omega$-guanidino nitrogen atoms on arginine residues in eukaryotes [94]. Table 3 summarizes common histone-lysine methylation marks, their effects on gene transcription, and the methyltransferases responsible for their generation.

Until the relatively recent discovery of specific lysine demethylating enzymes, it was considered that histone methylation was stable and irreversible. However, it is now known that this is not the case. There are two main classes of histone-lysine demethylating enzymes (Table 4). Lysinespecific demethylases (LSDs) utilize flavin adenosine dinucleotide (FAD) as a cofactor. The best studied LSD, LSD1, functions with protein complexes such as the CoREST (restin corepressor) complex to reverse $\mathrm{H} 3 \mathrm{~K} 4$ and $\mathrm{H} 3 \mathrm{~K} 9$ methylation [95-97]. The JmjC domain-containing proteins are the most recently discovered and the largest class of histone demethylases. They catalyze histone-lysine demethylation by utilizing $\mathrm{Fe}(\mathrm{II})$ and $\alpha$-ketoglutarate as cofactors [98]. Arginine demethylating enzymes have also been described [99], although, in comparison, the effects on gene transcription are more prevalent for histone-lysine demethylation.

As an illustration of the specificity of histone-lysine methylation, the $\mathrm{H} 3 \mathrm{~K} 4$ and $\mathrm{H} 3 \mathrm{~K} 36$ marks are associated with transcriptional activation, whereas the $\mathrm{H} 3 \mathrm{~K} 9$ and H3K27 marks are associated with transcriptional repression [100]. H3K4 monomethylation (H3K4me1)

Table 3 Histone-lysine methylation marks, their enzymatic writers, and their effects on gene transcription

\begin{tabular}{|c|c|c|}
\hline $\begin{array}{l}\text { Histone-lysine } \\
\text { methylation } \\
\text { mark }\end{array}$ & Function & Enzymatic writers (histone methyltransferases) \\
\hline $\mathrm{H} 3 \mathrm{~K} 4$ & Transcriptional activation & $\begin{array}{l}\text { MLL1/KMT2A, MLL2/KMT2B, MLL3/KMT2C, MLL4/KMT2D, MLL5/KMT2E, SET1A/ } \\
\text { KMT2F } \\
\text { SET1B/KMT2G, ASH1/KMT2H, SET7/9/KMT7 } \\
\text { SMYD1/KMT3D, SMYD2/KMT3C, SMYD3, SETMAR, PRDM9/KMT8B }\end{array}$ \\
\hline H3K9 & $\begin{array}{l}\text { Heterochromatin forma- } \\
\text { tion/transcriptional } \\
\text { repression }\end{array}$ & $\begin{array}{l}\text { SUV39H1/KMT1A, SUV39H2/KMT1B, EHMT2/G9a/KMT1C, EHMT1/GLP/KMT1D, ESET/ } \\
\text { SETDB1/KMT1E, }\end{array}$ \\
\hline H3K27 & Transcriptional repression & EZH1/KMT6B, EZH2/KMT6A \\
\hline H3K36 & Transcriptional activation & $\begin{array}{l}\text { SETD2/KMT3A, NSD1/KMT3B, SYMD2/KMT3C, SETMAR, NSD2/KMT3G, NSD3/KMT3F, } \\
\text { SETD3 }\end{array}$ \\
\hline H3K79 & Transcriptional activation & DOT1L/KMT4 \\
\hline $\mathrm{H} 4 \mathrm{~K} 20$ & $\begin{array}{l}\text { Transcriptional repres- } \\
\text { sion/DNA damage } \\
\text { response }\end{array}$ & SET8/KMT5A, SUV4-20H1/KMT5B, SUV4-20H2/KMC5C \\
\hline
\end{tabular}

Adapted from Refs. [6, 52, 169]

$M L L$ mixed lineage leukemia or myeloid/lymphoid leukemia, KMT K-methyltransferase, SMYD SET and MYND domain-containing, SETMAR SET domain and mariner transposase fusion protein, PRDM PR domain, SUV39H suppressor of variegation 3-9 homolog, EHMT euchromatic histone-lysine $N$-methyltransferase, GLP G9a-like protein, ESET ERG-associated protein with SET domain, SETDB SET domain bifurcated, EZH enhancer of zeste homolog, SETD SET domain-containing, NSD nuclear receptor-binding SET domain protein, DOT1L DOT1-like histone-lysine methyltransferase 
Table 4 Histone-lysine demethylases and substrates

\begin{tabular}{lll}
\hline Enzyme & Alternative name & Substrate demethylated \\
\hline LSD1 & KDM1A & H3K4me1/2, H3K9me1/2 \\
LSD2 & KDM1B & H3K4me1/2 \\
NO66 & & H3K4me1/2/3, H3K36me2/3 \\
JHDM1B/FBXL10 & KDM2B & H3K4me3, H3K36me1/2 \\
JARID1A/RBP2 & KDM5A & H3K4me2/3 \\
JARID1B/PLU-1 & KDM5B & H3K4me1/2/3 \\
JARID1C/SMCX & KDM5C & H3K4me2/3 \\
JARID1D/SMCY & KDM5D & H3K4me2/3 \\
JHDM2A & KDM3A & H3K9me1/2 \\
JHDM2B & KDM3B & H3K9me1/2/3 \\
JHDM2C & KDM3C & H3K9me1/2 \\
JMJD2A/JMJD3A & KDM4A & H3K9me3/2, H3K36me2/3 \\
JMJD2B & KDM4B & H3K9me2/3, H3K36me2/3 \\
JMJD2C/GASC1 & KDM4C & H3K9me2/3, H3K36me2/3 \\
JMJD2D & KDM4D & H3K9me2/3 \\
PHF2 & KDM7C & H3K9me1/2, H3K27me1/2 \\
PHF8 & KDM7B & H3K9me1/2, H4K20me1 \\
JHDM1D & KDM7A & H3K9me1/2, H3K27me1/2 \\
UTX & KDM6A & H3K27me2/3 \\
JMJD3 & KDM6B & H3K27me2/3 \\
JHDM1A/FBXL11 & KDM2A & H3K36me1/2 \\
\hline
\end{tabular}

Adapted from Refs. [52, 169-171]

LSD lysine-specific histone demethylase, KDM K-demethylase, $J H D M$ jumonji $\mathrm{C}$ domain-containing histone demethylase, $F B X L$ F-box and leucine-rich repeat protein, JARID jumonji/ARID domaincontaining protein, $R B P 2$ retinoblastoma-binding protein $2, S M C X$ Smcx homolog, X chromosome, SMCY SMC homolog, Y chromosome, JMJD jumonji domain-containing, GASCl gene amplified in squamous cell carcinoma $1, P H F$ PHD finger protein, $U T X$ ubiquitously transcribed $\mathrm{X}$ chromosome tetratricopeptide repeat protein

is commonly found at enhancer elements, whereas $\mathrm{H} 3 \mathrm{~K} 4$ trimethylation $(\mathrm{H} 3 \mathrm{~K} 4 \mathrm{me} 3)$ is enriched at active promoters [101]. H3K4me3 sites differ markedly between failing hearts and normal hearts both in Dahl salt-sensitive rats and in humans with congestive heart failure [102]. The histone methyltransferase protein complex responsible for H3K4 trimethylation associates with a ubiquitously expressed nuclear factor, termed pax transcription activation domain-interacting protein (PTIP) [103]. The murine model of hypertrophic heart failure induced by transverse aortic constriction (TAC) surgery is commonly employed to examine the effects of epigenetic changes on cardiac dysfunction, and mice lacking PTIP have diminished global $\mathrm{H} 3 \mathrm{~K} 4 \mathrm{me} 3$ levels and exhibit a maladaptive response to TAC [104]. This maladaptive response is characterized by cardiac dilatation, decreased left ventricular function, cardiac fibrosis, and increased cell death [104]. The JmjC domain-containing histone demethylase
JMJD2A catalyzes the demethylation of di- and tri- methylated $\mathrm{H} 3 \mathrm{~K} 9(\mathrm{H} 3 \mathrm{~K} 9 \mathrm{me} 2 / 3)$ and di- and tri- methylated H3K36 (H3K36me2/3). Mice with cardiac-specific inactivation of JMJD2A have been reported to have an attenuated hypertrophic response to pressure overload induced by TAC, whereas JMJD2A overexpressing mice have an exaggerated response [105].

\section{Histone phosphorylation, ubiquitination, SUMOylation, ADP ribosylation, and glycosylation}

Histone proteins may be phosphorylated on hydroxyl groups of serine, threonine, and tyrosine residues. Kinases catalyze the addition of phosphate groups from ATP and phosphatases catalyze their removal. Because phosphate groups confer a negative charge, phosphorylation, in general, is associated with open chromatin and thus facilitates gene transcription [106]. The kinase, calcium/calmodulin-dependent protein kinase II $\delta$ (CaMKII $\delta$ ) plays a key role in pathological cardiac hypertrophy [107]. It has been suggested that nuclear CaMKIII facilitates chromatin remodeling by phosphorylating H3Ser10, promoting the transcription of genes responsible for the hypertrophic response [108, 109].

Histone modifications can also involve the addition or removal of large bulky groups, specifically ubiquitination and SUMOylation. Ubiquitination entails the addition of the large polypeptide, ubiquitin by the sequential action of E1-activating, E2-conjugating, and E3-ligating enzymes, and the sites and degree of ubiquitination depend upon the enzyme complexes involved [110]. The addition of small ubiquitin-l modifier (SUMO) proteins also involves E1, E2, and E3 enzymes, and functions to prevent acetylation or ubiquitination at the same sites [111]. ADP ribosylation and glycosylation may also occur on amino acid residues on histone tails, although the extent to which these modifications may affect gene expression is relatively unexplored [112, 113]. There is also a comparative paucity of information pertaining to these other post-translational histone modifications and their relationship to heart failure.

\section{Epigenomic organization and the generation of developmental stage- and disease-specific epigenetic signatures}

Recently, efforts have been made to develop comprehensive epigenomic roadmaps in experimental and human heart disease. These approaches have combined chromatin immunoprecipitation (ChIP)-sequencing for multiple different histone marks together with transcriptional analysis determined after RNA-sequencing with or without ascertainment of DNA methylation and hydroxymethylation patterns by 
whole-genome bisulfite sequencing and $5 \mathrm{hmC}$-sequencing [114, 115]. In 2013, Papait and co-workers studied cardiomyocytes isolated from mice subjected to TAC, combining data from ChIP-sequencing for seven different histone marks (H3K9ac, H3K27ac, H3K4me3, H3K79me2, H3K9me2, $\mathrm{H} 3 \mathrm{~K} 9 \mathrm{me} 3$, and $\mathrm{H} 3 \mathrm{~K} 27 \mathrm{me} 3$ ) and RNA-sequencing data. Taking this approach, they identified a particular epigenetic signature that regulated the promoter activity of 325 of 1109 genes in experimental hypertrophic heart failure that was characterized by the mutual exclusion of histone modifications that mark areas of transcriptional activation (H3K9ac, $\mathrm{H} 3 \mathrm{~K} 27 \mathrm{ac}, \mathrm{H} 3 \mathrm{~K} 4 \mathrm{me} 3$, and H3K79me2) and repression (H3K9me2, H3K9me3, and H3K27me3) [114]. They also identified more than 9000 possible active enhancers associated with experimental cardiac hypertrophy [114]. More recently, Gilsbach and colleagues set out to examine the epigenomic signature of human cardiomyocytes during development, postnatal maturation, and in chronic heart failure. The investigators purified cardiomyocyte nuclei from human cardiomyocytes and subjected the samples to whole-genome bisulfite sequencing, $5 \mathrm{hmC}$-sequencing, ChIP-sequencing for seven histone marks (H3K27ac, H3K9ac, H3K36me3, H3 K4me1, H3K4me3, H3K9me3, and H3K27me3), and RNA-sequencing for nuclear gene expression. They reported that prenatal development and postnatal maturation are characterized by active $\mathrm{CpG}$ methylation and histone marks at cis-regulatory and genic regions, but that, in heart failure, there are changes in active histone marks without major changes in $\mathrm{CpG}$ methylation. These active histone marks were H3K27ac, H3K4me3, H3K4me1, H3K9ac, and H3K36me3 [115]. The findings highlight the close interrelationship between DNA methylation patterns and histone modifications, and underscore the paradigm that, once they are established, DNA methylation patterns are highly stable, whereas histone modifications are more labile [74]. The derivation of epigenomic blueprints such as these may aid the development of future treatments, for instance, by facilitating the generation of cardiomyocytes from embryonic stem cells or induced pluripotent stem cells or by facilitating the epigenomic reprogramming of cells into cardiomyocytes in vivo [115].

\section{Histone protein modifications and heart failure in diabetes}

In Table 5, we have summarized some of the most salient studies of the roles of histone proteins in heart failure. Of these 22 studies, 6 have focused on the roles of histone protein post-translational modifications in diabetes and they are elaborated upon here. One of the first reports describing alterations in histone protein modifications in the diabetic heart examined global histone changes in the hearts of uninephrectomized Type 2 diabetic $\mathrm{db} / \mathrm{db}$ mice and reported an overall change in the cardiac histone signature in diabetes (i.e. increased levels of H3K23ac, H3K9ac, H3Ser10 phosphorylation, and $\mathrm{H} 3 \mathrm{~K} 4 \mathrm{me} 2$ and reduced levels of $\mathrm{H} 3 \mathrm{~K} 9 \mathrm{me} 2$ ) [116]. In the context of our current understanding of the complexity of epigenomic organization, the significance of overall global changes in these histone marks is uncertain. Concurrently, experiments in the H9c2 rat cardiomyocyte cell line have suggested that high glucose levels can themselves induce specific alterations in histone marks at the sites of genes encoding proteins important for cardiomyocyte survival and inflammation. For instance, high glucose has been proposed as being responsible for an HDAC1-dependent diminution in histone $\mathrm{H} 4$ acetylation at the insulin-like growth factor-1 receptor (IGF-1R) promoter that resulted in a decrease in IGF-1R expression accompanied by enhanced programmed cell death [117]. The same investigators followed this work up by demonstrating that transient exposure of H9c2 cells to high glucose caused decreased levels of the repressive $\mathrm{H} 3 \mathrm{~K} 9$ me 3 mark (and the $\mathrm{H} 3 \mathrm{~K} 9$ trimethylating enzyme SUV39H1) at the promoter region of the proinflammatory cytokine interleukin-6 (IL-6), resulting in persistent IL-6 upregulation [118].

In vivo, treatment of fructose-fed diabetic rats with resveratrol deacetylated both the p65 subunit of nuclear factor kappa-light-chain-enhancer of activated B cells (NF- $\mathrm{kB}$ ) and $\mathrm{H} 3 \mathrm{~K} 9$, and attenuated cardiac hypertrophy and oxidative stress through downregulation of NADPH oxidase [119]. Separately, activity of the Class I HDAC, HDAC3 was found to be significantly increased in the hearts of Type 1 diabetic OVE26 mice, whereas selective HDAC3 inhibition improved diabetes-induced cardiac dysfunction [120]. In that study, HDAC3 inhibition led to the acetylation of histone $\mathrm{H} 3$ at the promoter region of the gene encoding the nuclear ERK1/2 phosphatase, dual specificity phosphatase 5 (DUSP5), preventing diabetes-associated DUSP5 downregulation, which the authors speculated was responsible for ERK1/2-driven cardiac dysfunction in diabetes [120]. A number of other studies have reported an improvement in the cardiac phenotype of diabetic rodents treated with pharmacological agents that influence the activity of HAT [121, 122] or HDAC enzymes [123-126]. However, because of the breadth of their enzymatic substrates, it is difficult to determine which, if any, of their effects are mediated through the post-translational modification of histone proteins.

With respect to histone modification changes that occur in people with diabetes, cardiac mesenchymal cells obtained from individuals with Type 2 diabetes have been characterized as having diminished H3Ser10 phosphorylation levels accompanied by decreased differentiation potential, reduced proliferation, and premature senescence [127]. This observation is significant, because it serves to highlight the dual functionality of H3Ser10 phosphorylation. On one hand, 


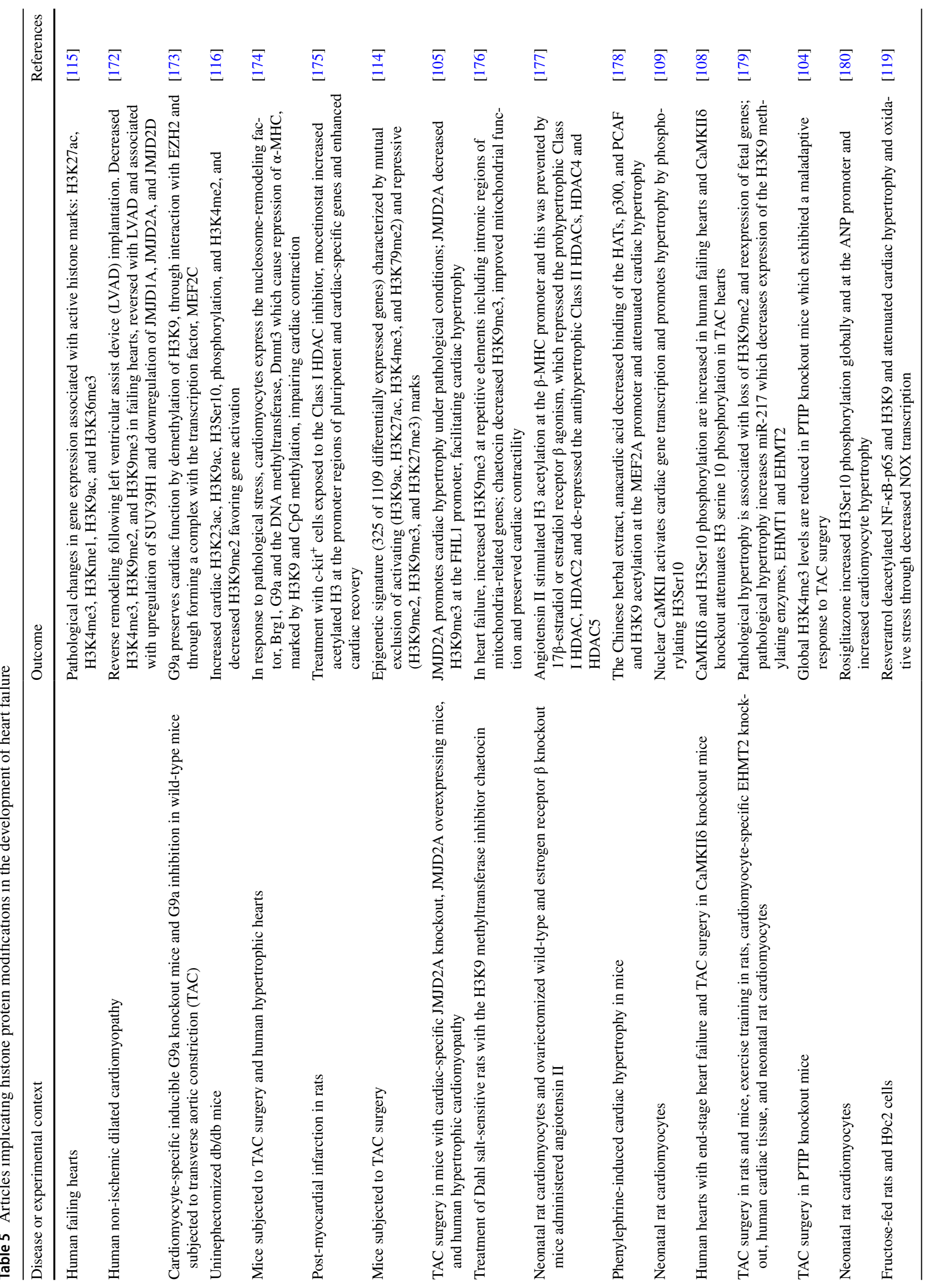




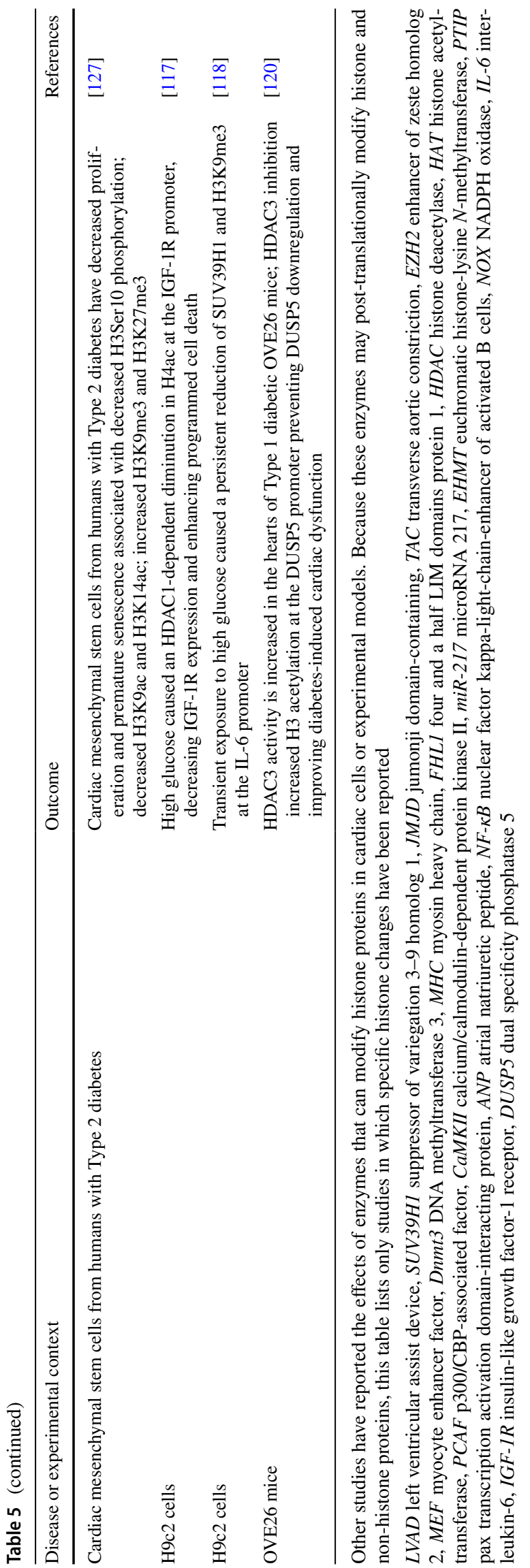

H3Ser10 phosphorylation associates with open chromatin and facilitates gene transcription during interphase. On the other hand, it marks highly condensed chromatin during mitosis, peaking during metaphase [128, 129], and it may, therefore, be used as a marker of cellular proliferation. Aside from these changes in histone phosphorylation, cardiac mesenchymal cells from individuals with Type 2 diabetes also exhibited a specific histone signature characterized by a predominance of histone marks associated with transcriptional repression (H3K9me3, H3K27me3, and H3K20me3) together with a decrease in histone marks typically associated with active chromatin (H3K9ac and H4K16ac) [127]. Moreover, treatment with a GNAT proactivator was able to restore $\mathrm{H} 3 \mathrm{~K} 9 \mathrm{ac}$ and $\mathrm{H} 4 \mathrm{~K} 16 \mathrm{ac}$ levels, and improve the proliferation and differentiation of cardiac mesenchymal cells derived from individuals with Type 2 diabetes [127].

\section{The role of histone protein modifications in pathogenetic processes important to the development of heart failure in diabetes but studied in non-cardiac cells}

Although numerous studies have pointed to the importance of histone protein modifications in the development of heart failure, relatively few have examined their effects in heart failure in diabetes. This may be, at least in part, due to the limitations imposed by current models of cardiac dysfunction in diabetes. In particular, it is noteworthy that much of the current evidence indicating that histone protein posttranslational modifications can affect cardiac function is derived from studies that have employed the TAC model of hypertrophic heart failure (Table 5). LVH is also a common predeterminant of heart failure in people with diabetes [130]. However, it is typically absent in rodent models of diabetes. For instance, the most widely studied model of diabetes and cardiac dysfunction is the streptozotocin-induced diabetes model, yet these animals do not develop cardiac hypertrophy [131] and the most commonly studied model of Type 2 diabetes is the $\mathrm{db} / \mathrm{db}$ mouse [131], yet $\mathrm{db} / \mathrm{db}$ mice appear to be relatively protected from cardiac dysfunction induced by TAC surgery [130]. Thus, the limitations of current experimental models may impede elucidation of the role of histone modifications in heart failure in diabetes. In this context, is it instead possible to derive clues as to their potential roles by examining the effects of histone post-translational modifications in other diabetes complications that are caused by similar pathogenetic processes?

\section{Fibrosis}

Fibrosis is a common end process in heart failure, including in the diabetic setting [132]. Whereas little is known about 
the influence of histone protein modifications on cardiac fibrosis in diabetes, their effects on fibrosis of the diabetic kidney have been explored (reviewed in Ref. [133]). Here, we highlight two examples in which specific histone modifications have been found to promote fibrotic gene expression in renal cells. In a seminal report published in 2010, Sun and co-workers probed for changes in histone methylation marks at the promoter regions of genes encoding extracellular matrix proteins in rat glomerular mesangial cells exposed to the profibrotic growth factor, transforming growth factor- $\beta 1$ (TGF- $\beta 1$ ) [126]. The investigators found increased levels of chromatin marks associated with active genes (i.e., H3K4me1-3, accompanied by increased expression and recruitment of the H3K4 methyltransferase SET7/9) and decreased levels of marks associated with gene repression (i.e., H3K9me2 and $\mathrm{H} 3 \mathrm{~K} 9 \mathrm{me} 3$ ), whereas treatment of high glucose exposed cells with a neutralizing TGF- $\beta 1$ antibody prevented these histone changes [126]. Separately, myocardin-related transcription factor-A (MRTF-A) is a serum response factor cofactor that promotes cardiac myofibroblast activation and fibrosis [134]. In diabetic mice, deletion of MRTF-A attenuated renal tubulointerstitial fibrosis and was accompanied by the loss of histone modifications indicative of transcriptional activation (i.e., H3K18ac, H3K27ac, and H3K4me3) [135]. These effects, in renal epithelial cells exposed to high glucose, were attributed to the recruitment by MRTF-A of both the histone acetyltransferase, p300, and a component of the H3K4 methyltransferase complex, WD repeat-containing protein 5 to the promoter regions of target fibrotic genes [135].

\section{Advanced glycation end products}

Advanced glycation end products are formed when nonenzymatic reactions take place between reducing sugars and free amino groups of proteins, lipids, or nucleic acids [136]. Because they are stable and long lasting, AGEs have been implicated in the development and progression of many of the long-term complications of diabetes [137], including heart failure [132]. AGEs may directly modify histone proteins, and this may directly affect chromatin structure and gene expression $[138,139]$. The effects of AGEs may also themselves be influenced by histone protein modifications. For instance, in monocytes, the induction of inflammatory genes by ligands of the receptor for advanced glycation end products (RAGE) was attenuated by knockdown of SET7/9 [140].

\section{Oxidative stress}

Studies have demonstrated a bidirectional association between histone modifications and oxidative stress in diabetes, whereby, on one hand, reactive oxygen species
(ROS) may influence the formation of new histone modifications under high glucose conditions, and, on the other hand, histone modifications may influence the development of oxidative stress. As an illustration of how ROS may influence histone modifications, El-Osta and co-workers demonstrated the effects of transient exposure of aortic endothelial cells to high glucose on histone changes at the promoter region of the gene encoding the $\mathrm{p} 65$ subunit of the proinflammatory nuclear factor, NF- $\mathrm{BB}$ [141]. They found that high glucose caused persistent p65 upregulation that was mediated by SET7-induced histone H3K4 monomethylation [141]. This persistent upregulation of p65 was prevented by overexpression of either uncoupling protein-1 or manganese superoxide dismutase (MnSOD), which both prevent high glucose-induced superoxide accumulation, or by overexpression of glyoxalase 1, which metabolizes methylglyoxal a precursor of AGEs [141]. In contrast, in rat retinal endothelial cells, regulation of the gene encoding MnSOD is itself associated with specific chromatin modifications under diabetic conditions (i.e., H4K20me3 and H3K9ac) [142]. Our own work on histone modifications and oxidative stress in diabetes has focused on the regulation of enzymatic antioxidant repair mechanisms. Thioredoxin-interacting protein (TxnIP) is a glucose-regulated inhibitor of the endogenous antioxidant enzyme, thioredoxin. TxnIP is upregulated in both the diabetic kidney [143] and the diabetic heart [144], and it predisposes to diabetes-associated oxidative damage [143, 144]. In mouse glomerular podocytes, depletion of the histone H3K27 trimethylating enzyme enhancer of zeste homolog 2 (EZH2) was accompanied by de-repression of TxnIP and augmented oxidative injury [145]. Interestingly, however, in these studies, we did not find the repressive H3K27me3 mark at the mouse TxnIP promoter; rather, EZH2 depletion caused loss of H3K27me3 at the promoter region of the gene encoding the transcription factor Pax6 associated with de-repression of Pax6 which subsequently bound to the TxnIP promoter controlling expression of its gene product [145].

\section{Endothelial dysfunction}

TxnIP may itself also influence endothelial dysfunction in diabetes by inducing histone modifications. In rat retinal endothelial cells, for example, RAGE activation upregulated cyclooxygenase-2 (COX-2) in a TxnIP-dependent manner and TxnIP overexpression caused an increase in the H3K9ac mark (associated with transcriptional activation) and a decrease in the H3K9me3 mark (associated with transcriptional repression) at the proximal COX-2 promoter [146]. $\mathrm{p} 66^{\mathrm{Shc}}$ is an adaptor protein that contributes to mitochondrial ROS generation by accepting 
electrons from cytochrome c. In endothelial cells, the class III HDAC, SIRT1 binds to the $\mathrm{p} 66^{\text {Shc }}$ promoter region, causing a decrease in histone $\mathrm{H} 3$ acetylation, repressing $\mathrm{p} 66^{\text {Shc }}$ and protecting against hyperglycemia-induced endothelial dysfunction [147]. In individuals with Type 2 diabetes, intensive glycemic control did not improve brachial artery flow-mediated dilatation and, associated with this persistent abnormality in endothelial function, there was persistent downregulation of SIRT1 and of histone $\mathrm{H} 3$ acetylation at the $\mathrm{p} 66^{\mathrm{Shc}}$ promoter (along with DNA hypomethylation) [148].

\section{Inflammation}

A number of examples already cited above have explored the contributions of histone protein modifications to the long-term complications of diabetes in the context of inflammation. Elsewhere, in glomerular podocytes, the class III HDAC, SIRT6 limits inflammation and deacetylates H3K9 at the promoter regions of the Notch ligands, Notch1 and Notch4 [149]; the proinflammatory phenotype of macrophages in Type 2 diabetes has been attributed to a
Jmjd3-mediated loss of the repressive H3K27me3 mark at the promoter region of the gene encoding IL-12 [150]; and vascular smooth muscle cells (VSMCs) from $\mathrm{db} / \mathrm{db}$ mice exhibited loss of the repressive $\mathrm{H} 3 \mathrm{~K} 9 \mathrm{me} 3$ histone mark at the promoter regions of key proinflammatory genes, as did human VSMCs exposed to high glucose [151].

\section{Glucose metabolism, fatty acid utilization, and small vessel disease}

The roles that epigenetic processes play in glucose metabolism and fatty acid utilization have recently been reviewed elsewhere [152-154]. With respect to small vessel disease, histone protein changes have been observed at the gene encoding matrix metalloproteinase-9 (MMP-9), which augments retinal capillary cell programmed cell death. More particularly, Zhong and co-workers found decreased levels of the repressive $\mathrm{H} 3 \mathrm{~K} 9 \mathrm{me} 2$ mark and increased levels of the activating H3K9ac mark at the MMP-9 promoter in high glucose exposed retinal endothelial cells [155]. This effect was attributed by the authors to diabetes-induced increases in the expression and activity of LSD1 which demethylates

\section{Diabetes and comorbid conditions}

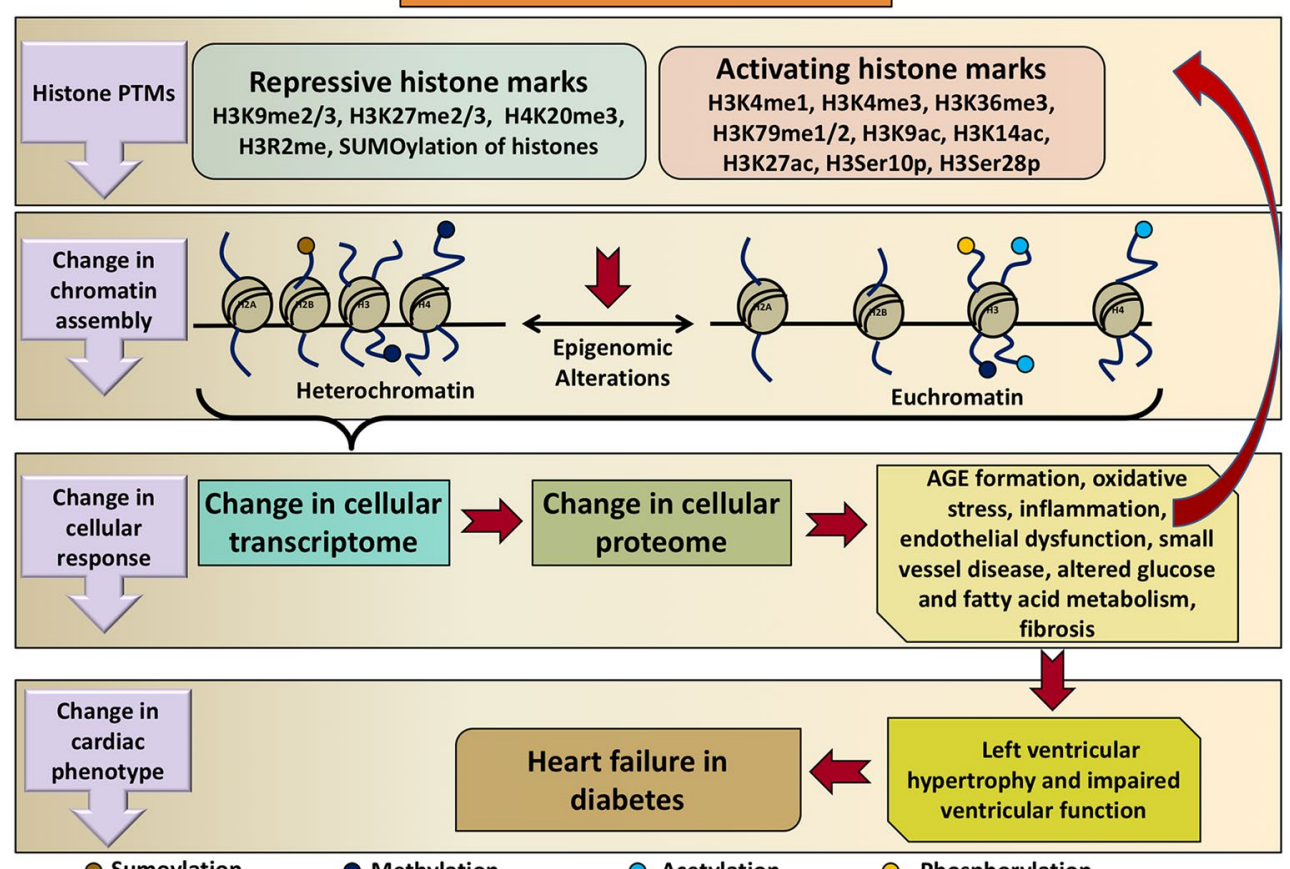

Fig. 3 Schematic illustration of the roles that histone protein posttranslational modifications may play in the development of heart failure in diabetes. Diabetes and its comorbidities cause changes in repressive and activating histone marks that alter chromatin assembly. This in turn affects the cellular transcriptome and proteome promoting cellular injury processes in diabetes. These processes can themselves affect histone protein modifications. The result is a change in cardiac phenotype leading to left ventricular hypertrophy and dysfunction and thus heart failure in diabetes. PTM post-translational modification, H3R2me methylation of arginine 2 on histone $\mathrm{H} 3$, H3Ser 10p phosphorylation of serine residue 10 on histone H3, H3Ser $28 p$ phosphorylation of serine residue 28 on histone $\mathrm{H} 3, A G E$ advanced glycation end product 
$\mathrm{H} 3 \mathrm{~K} 9$ me2, freeing up $\mathrm{H} 3 \mathrm{~K} 9$ for acetylation and, in turn, facilitating the recruitment of p65, upregulating MMP-9, and predisposing to mitochondrial damage and cell death [155].

In summary, a body of literature evidence exists attesting to the roles that histone protein post-translational modifications play in the development of heart failure and a comparable body of literature exists attesting to their contributions to end-organ injury in diabetes. Evidence is likewise beginning to emerge linking histone modifications specifically to the development of heart failure in diabetes. The putative mechanisms through which this may occur are summarized in Fig. 3. It is noteworthy, however, that one of the defining characteristics of histone modifications is that they are lineage-specific [156]. Thus, caution should be taken in extrapolating findings from other model systems and the determination of the extent to which histone modifications do contribute to the development of heart failure in diabetes requires further direct experimentation.

\section{Future directions: therapeutically targeting histone-modifying enzymes in the clinic}

Whereas the understanding of the fundamental mechanisms of disease is creditable in its own right, the evolving diabetes pandemic and the grim prognosis of those individuals who develop heart failure in diabetes demand our earnest efforts to seek out new treatment opportunities. Thus, what evidence exists that histone protein modifications can be amenable to therapeutic manipulation in patients? A number of therapies that target histone-modifying enzymes have received regulatory authority approval or are undergoing clinical trial evaluation (Table 6). In most cases, these agents are currently undergoing evaluation, or have been approved, for the treatment of various malignancies, particularly hematological malignancies.

If the therapeutic manipulation of histone protein modifications is going to find a place in the treatment of heart failure in diabetes advances need to be made at both the fundamental and pharmacological levels. As has already been highlighted, evidence exists that histone protein posttranslational modifications are awry in heart failure and in other long-term complications of diabetes. However, much needs to be done to better understand their relative contributions to the development of heart failure in diabetes. This will require animal models that better recapitulate the human disease state and a recognition that humans and rodents will likely differ in their disease-specific epigenomes [157]. At the pharmacological level, the therapies that are most advanced in their clinical development are inhibitors of HDAC enzymes and inhibitors of the H3K27 trimethylating enzyme, EZH2 (Table 6). As already emphasized, at least in the former case, given the breadth of their potential substrates, the biologic effects of HDAC inhibitors in the clinic cannot be assumed to be mediated solely by the acetylation of histone proteins. Furthermore, these agents may have adverse effect profiles that, whilst tolerable in the cancer setting, are unacceptable for the treatment of chronic disease. For instance, the most common adverse effects of the HDAC inhibitor vorinostat (occurring with an incidence $\geq 20 \%$ ) are diarrhea, nausea, anorexia, fatigue, thrombocytopenia, and dysgeusia [158]. Finally, most of the currently

Table 6 Approved therapies and therapies under clinical trial evaluation whose mechanism of action involves the inhibition of histone-modifying enzymes

\begin{tabular}{llll}
\hline Therapy & Class & Latest stage of development & Indication or National Clinical Trial identifier number \\
\hline $\begin{array}{lll}\text { Vorinostat } \\
\text { Romidepsin }\end{array}$ & HDAC inhibitor & FDA approved & Cutaneous T cell lymphoma \\
& HDAC inhibitor & FDA approved & Cutaneous T-cell lymphoma and other peripheral \\
Belinostat & HDAC inhibitor & FDA approved & Peripheral T-cell lymphoma \\
Panobinostat & HDAC inhibitor & FDA approved & Multiple myeloma \\
Chidamide & HDAC inhibitor & Approved in China & Relapsed or refractory T-cell lymphoma \\
Entinostat & HDAC inhibitor & Phase 3 & NCT02115282 \\
Tazemetostat & EZH2 inhibitor & Phase 2 & NCT018975751, NCT02875548, NCT02601950 \\
Givinostat & HDAC inhibitor & Phase 2 & NCT01761968 \\
Mocetinostat & HDAC inhibitor & Phase 2 & NCT0205660, NCT02954991 \\
Tinostamustine & First-in-class alkylating HDAC & Phase $1 / 2$ & NCT03345485 \\
INCB059872 & inhibitor & & \\
DS-3201b & EZH1 inhibitor & Phase $1 / 2$ & NCT02712905 \\
CXD101 & HDAC inhibitor & Phase 1 & NCT02732275 \\
MPT0E028 & HDAC inhibitor & Phase 1 & NCT01977638 \\
CPI-1205 & EZH2 inhibitor & Phase 1 & NCT02350868 \\
\hline
\end{tabular}


utilized HDAC inhibitors lack HDAC specificity. Vorinostat, for instance, inhibits Class I HDACs (HDAC1, HDAC2, and HDAC3) and Class II HDACs (HDAC6) at low nanomolar concentrations $(<86 \mathrm{nM})$ [159]. Whereas other HDAC inhibitors may inhibit solely Class I HDACs (e.g., mocetinostat and entinostat) [160,161], the development of isoform-specific agents is still in its relative infancy [162-165]. Whether it will be possible to develop agents with sufficient tolerability and with sufficient specificity that they can be used for the treatment of complex chronic diseases, such as heart failure, remains to be seen.

\section{Summary}

It is 15 years, since Dr. David Bell described heart failure as "the frequent, forgotten, and often fatal complication of diabetes" [4]. Although the results of recent outcome trials assure that heart failure may, perhaps, no longer be the forgotten complication of diabetes, it remains frequent and often fatal. Histone protein modifications have emerged as pivotal players in both the development of diabetes-associated injury to other organ systems and in heart failure that is not caused by diabetes, especially hypertrophic heart failure which is a common occurrence in patients with diabetes. Histone protein post-translational modifications are amenable to therapeutic manipulation and there is a rapidly proliferating armamentarium of small molecule pharmaceuticals that alter these processes and that are under investigation in other disease settings. It remains to be seen whether altered histone protein modifications may be amenable enough or whether any of the existing or future tools will be specific enough or tolerable enough to improve outcomes for the millions of individuals currently affected by heart failure in diabetes.

Acknowledgements We apologize to the authors of the many excellent articles related to histone post-translational modifications and heart failure that have been omitted due to space constraints. This work was supported by a Grant-in-Aid from the Heart and Stroke Foundation of Canada to AA (G-17-0018231). AA is a recipient of a Diabetes Investigator Award from Diabetes Canada.

\section{Compliance with ethical standards}

Conflict of interest AA has received research support through his institution from Boehringer Ingelheim and AstraZeneca, and is listed as an inventor on a patent application filed by Boehringer Ingelheim on the treatment of heart failure.

Open Access This article is distributed under the terms of the Creative Commons Attribution 4.0 International License (http://creativeco mmons.org/licenses/by/4.0/), which permits unrestricted use, distribution, and reproduction in any medium, provided you give appropriate credit to the original author(s) and the source, provide a link to the Creative Commons license, and indicate if changes were made.

\section{References}

1. Tsilidis KK, Kasimis JC, Lopez DS, Ntzani EE, Ioannidis JP (2015) Type 2 diabetes and cancer: umbrella review of metaanalyses of observational studies. BMJ 350:g7607

2. Li W, Huang E (2016) An update on type 2 diabetes mellitus as a risk factor for dementia. J Alzheimers Dis 53:393-402

3. Wang J, You W, Jing Z, Wang R, Fu Z, Wang Y (2016) Increased risk of vertebral fracture in patients with diabetes: a meta-analysis of cohort studies. Int Orthop 40:1299-1307

4. Bell DS (2003) Heart failure: the frequent, forgotten, and often fatal complication of diabetes. Diabetes Care 26:2433-2441

5. Keating ST, Plutzky J, El-Osta A (2016) Epigenetic changes in diabetes and cardiovascular risk. Circ Res 118:1706-1722

6. Keating ST, van Diepen JA, Riksen NP, El-Osta A (2018) Epigenetics in diabetic nephropathy, immunity and metabolism. Diabetologia 61:6-20

7. Kato M, Natarajan R (2014) Diabetic nephropathy-emerging epigenetic mechanisms. Nat Rev Nephrol 10:517-530

8. Kowluru RA, Santos JM, Mishra M (2013) Epigenetic modifications and diabetic retinopathy. Biomed Res Int 2013:635284

9. Pasquier J, Hoarau-Vechot J, Fakhro K, Rafii A, Abi Khalil C (2015) Epigenetics and cardiovascular disease in diabetes. Curr Diab Rep 15:108

10. Gillette TG, Hill JA (2015) Readers, writers, and erasers: chromatin as the whiteboard of heart disease. Circ Res 116:1245-1253

11. International Diabetes Federation (2017) IDF diabetes atlas, 8th edn. https://www.idf.org/e-library/epidemiology-research/ diabetes-atlas.html. Accessed 24 Jan 2018

12. Kannel WB, Hjortland M, Castelli WP (1974) Role of diabetes in congestive heart failure: the Framingham study. Am J Cardiol 34:29-34

13. Nichols GA, Gullion CM, Koro CE, Ephross SA, Brown JB (2004) The incidence of congestive heart failure in type 2 diabetes: an update. Diabetes Care 27:1879-1884

14. Rosengren A et al (2015) Long-term excess risk of heart failure in people with type 1 diabetes: a prospective case-control study. Lancet Diabetes Endocrinol 3:876-885

15. Dauriz M, Mantovani A, Bonapace S, Verlato G, Zoppini G, Bonora E, Targher G (2017) Prognostic impact of diabetes on long-term survival outcomes in patients with heart failure: a meta-analysis. Diabetes Care 40:1597-1605

16. Zhu J, Kahn P, Knudsen J, Mehta SN, Gabbay RA (2016) Predictive model for estimating the cost of incident diabetes complications. Diabetes Technol Ther 18:625-634

17. Dunlay SM, Roger VL, Redfield MM (2017) Epidemiology of heart failure with preserved ejection fraction. Nat Rev Cardiol 14:591-602

18. Mentz RJ et al (2014) Noncardiac comorbidities in heart failure with reduced versus preserved ejection fraction. J Am Coll Cardiol 64:2281-2293

19. Triposkiadis F, Giamouzis G, Parissis J, Starling RC, Boudoulas H, Skoularigis J, Butler J, Filippatos G (2016) Reframing the association and significance of co-morbidities in heart failure. Eur J Heart Fail 18:744-758

20. MacDonald MR et al (2008) Impact of diabetes on outcomes in patients with low and preserved ejection fraction heart failure: an analysis of the Candesartan in Heart failure: Assessment of Reduction in Mortality and morbidity (CHARM) programme. Eur Heart J 29:1377-1385

21. Rubler S, Dlugash J, Yuceoglu YZ, Kumral T, Branwood AW, Grishman A (1972) New type of cardiomyopathy associated with diabetic glomerulosclerosis. Am J Cardiol 30:595-602 
22. Aneja A, Tang WH, Bansilal S, Garcia MJ, Farkouh ME (2008) Diabetic cardiomyopathy: insights into pathogenesis, diagnostic challenges, and therapeutic options. Am J Med 121:748-757

23. Konduracka E, Gackowski A, Rostoff P, Galicka-Latala D, Frasik W, Piwowarska W (2007) Diabetes-specific cardiomyopathy in type 1 diabetes mellitus: no evidence for its occurrence in the era of intensive insulin therapy. Eur Heart J 28:2465-2471

24. Kannel WB, McGee DL (1979) Diabetes and cardiovascular risk factors: the Framingham study. Circulation 59:8-13

25. Suh DC, Kim CM, Choi IS, Plauschinat CA, Barone JA (2009) Trends in blood pressure control and treatment among type 2 diabetes with comorbid hypertension in the United States: 19882004. J Hypertens 27:1908-1916

26. Nassif M, Kosiborod M (2018) Effect of glucose-lowering therapies on heart failure. Nat Rev Cardiol 15:282-291

27. Marwick TH, Ritchie R, Shaw JE, Kaye D (2018) Implications of underlying mechanisms for the recognition and management of diabetic cardiomyopathy. J Am Coll Cardiol 71:339-351

28. Kasznicki J, Drzewoski J (2014) Heart failure in the diabetic population-pathophysiology, diagnosis and management. Arch Med Sci 10:546-556

29. Jia G, Hill MA, Sowers JR (2018) Diabetic cardiomyopathy: an update of mechanisms contributing to this clinical entity. Circ Res 122:624-638

30. Kannel WB (2000) Incidence and epidemiology of heart failure. Heart Fail Rev 5:167-173

31. Brinkley TE et al (2018) Long-term effects of an intensive lifestyle intervention on electrocardiographic criteria for left ventricular hypertrophy: the look AHEAD trial. Am J Hypertens 31:541-548

32. Yancy CW et al (2013) 2013 ACCF/AHA guideline for the management of heart failure: executive summary: a report of the American College of Cardiology Foundation/American Heart Association Task Force on practice guidelines. Circulation 128:1810-1852

33. Writing Committee $M$ et al (2016) 2016 ACC/AHA/HFSA focused update on new pharmacological therapy for heart failure: an update of the 2013 ACCF/AHA guideline for the management of heart failure: a report of the American College of Cardiology/American Heart Association Task Force on Clinical Practice Guidelines and the Heart Failure Society of America. Circulation 134:e282-e293

34. Iwano H, Little WC (2013) Heart failure: what does ejection fraction have to do with it? J Cardiol 62:1-3

35. DT Investigators et al (2008) Effects of ramipril and rosiglitazone on cardiovascular and renal outcomes in people with impaired glucose tolerance or impaired fasting glucose: results of the Diabetes REduction Assessment with ramipril and rosiglitazone Medication (DREAM) trial. Diabetes Care 31:1007-1014

36. Dormandy JA et al (2005) Secondary prevention of macrovascular events in patients with type 2 diabetes in the PROactive Study (PROspective pioglitAzone Clinical Trial In macroVascular Events): a randomised controlled trial. Lancet 366:1279-1289

37. Zannad F et al (2015) Heart failure and mortality outcomes in patients with type 2 diabetes taking alogliptin versus placebo in EXAMINE: a multicentre, randomised, double-blind trial. Lancet 385:2067-2076

38. Green JB et al (2015) Effect of sitagliptin on cardiovascular outcomes in type 2 diabetes. N Engl J Med 373:232-242

39. Pfeffer MA et al (2015) Lixisenatide in patients with type 2 diabetes and acute coronary syndrome. N Engl J Med 373:2247-2257

40. Marso SP et al (2016) Liraglutide and cardiovascular outcomes in type 2 diabetes. N Engl J Med 375:311-322

41. Marso SP et al (2016) Semaglutide and cardiovascular outcomes in patients with type 2 diabetes. N Engl J Med 375:1834-1844
42. Scirica BM et al (2013) Saxagliptin and cardiovascular outcomes in patients with type 2 diabetes mellitus. N Engl J Med 369:1317-1326

43. White WB et al (2013) Alogliptin after acute coronary syndrome in patients with type 2 diabetes. N Engl J Med 369:1327-1335

44. U.S. Food and Drug Administration. Guidance for Industry. Diabetes mellitus - evaluating cardiovascular risk in new antidiabetic therapies to treat type 2 diabetes, December 2008. https ://www.fda.gov/downloads/Drugs/GuidanceComplianceRegulat oryInformation/Guidances/ucm071627.pdf. Accessed 29 Jan 2018

45. Zinman B et al (2015) Empagliflozin, cardiovascular outcomes, and mortality in type 2 diabetes. N Engl J Med 373:2117-2128

46. Neal B et al (2017) Canagliflozin and cardiovascular and renal events in type 2 diabetes. N Engl J Med 377:644-657

47. Fitchett $\mathrm{D}$ et al (2016) Heart failure outcomes with empagliflozin in patients with type 2 diabetes at high cardiovascular risk: results of the EMPA-REG OUTCOME(R) trial. Eur Heart J 37:1526-1534

48. Krude T (1995) Chromatin. Nucleosome assembly during DNA replication. Curr Biol 5:1232-1234

49. Kalashnikova AA, Rogge RA, Hansen JC (2016) Linker histone $\mathrm{H} 1$ and protein-protein interactions. Biochim Biophys Acta 1859:455-461

50. Izzo A, Schneider R (2016) The role of linker histone H1 modifications in the regulation of gene expression and chromatin dynamics. Biochim Biophys Acta 1859:486-495

51. Bannister AJ, Kouzarides T (2011) Regulation of chromatin by histone modifications. Cell Res 21:381-395

52. Allis CD et al (2007) New nomenclature for chromatin-modifying enzymes. Cell 131:633-636

53. Christensen DP et al (2014) Lysine deacetylase inhibition prevents diabetes by chromatin-independent immunoregulation and beta-cell protection. Proc Natl Acad Sci USA 111:1055-1059

54. Lawrence M, Daujat S, Schneider R (2016) Lateral thinking: how histone modifications regulate gene expression. Trends Genet $32: 42-56$

55. Kouzarides T (2007) Chromatin modifications and their function. Cell 128:693-705

56. Swygert SG, Peterson CL (2014) Chromatin dynamics: interplay between remodeling enzymes and histone modifications. Biochim Biophys Acta 1839:728-736

57. Jaskelioff M, Gavin IM, Peterson CL, Logie C (2000) SWISNF-mediated nucleosome remodeling: role of histone octamer mobility in the persistence of the remodeled state. Mol Cell Biol 20:3058-3068

58. Vettese-Dadey M, Grant PA, Hebbes TR, Crane- Robinson C, Allis CD, Workman JL (1996) Acetylation of histone H4 plays a primary role in enhancing transcription factor binding to nucleosomal DNA in vitro. EMBO J 15:2508-2518

59. Bulger M, Groudine M (2011) Functional and mechanistic diversity of distal transcription enhancers. Cell 144:327-339

60. Kininis M, Chen BS, Diehl AG, Isaacs GD, Zhang T, Siepel AC, Clark AG, Kraus WL (2007) Genomic analyses of transcription factor binding, histone acetylation, and gene expression reveal mechanistically distinct classes of estrogen-regulated promoters. Mol Cell Biol 27:5090-5104

61. Soboleva TA, Nekrasov M, Ryan DP, Tremethick DJ (2014) Histone variants at the transcription start-site. Trends Genet 30:199-209

62. Clements A, Poux AN, Lo WS, Pillus L, Berger SL, Marmorstein R (2003) Structural basis for histone and phosphohistone binding by the GCN5 histone acetyltransferase. Mol Cell 12:461-473

63. Lo WS, Duggan L, Emre NC, Belotserkovskya R, Lane WS, Shiekhattar R, Berger SL (2001) Snf1-a histone kinase that 
works in concert with the histone acetyltransferase Gcn5 to regulate transcription. Science 293:1142-1146

64. Shi L et al (2011) Histone demethylase JMJD2B coordinates $\mathrm{H} 3 \mathrm{~K} 4 / \mathrm{H} 3 \mathrm{~K} 9$ methylation and promotes hormonally responsive breast carcinogenesis. Proc Natl Acad Sci USA 108:7541-7546

65. Holliday R, Pugh JE (1975) DNA modification mechanisms and gene activity during development. Science 187:226-232

66. Riggs AD (1975) X inactivation, differentiation, and DNA methylation. Cytogenet Cell Genet 14:9-25

67. Nan X, Campoy FJ, Bird A (1997) MeCP2 is a transcriptional repressor with abundant binding sites in genomic chromatin. Cell 88:471-481

68. Jones PA (2012) Functions of DNA methylation: islands, start sites, gene bodies and beyond. Nat Rev Genet 13:484-492

69. Tahiliani $\mathrm{M}$ et al (2009) Conversion of 5-methylcytosine to 5-hydroxymethylcytosine in mammalian DNA by MLL partner TET1. Science 324:930-935

70. Kriaucionis S, Heintz N (2009) The nuclear DNA base 5-hydroxymethylcytosine is present in Purkinje neurons and the brain. Science 324:929-930

71. Gan $\mathrm{H}$ et al (2013) Dynamics of 5-hydroxymethylcytosine during mouse spermatogenesis. Nat Commun 4:1995

72. Madzo J, Vasanthakumar A, Godley LA (2013) Perturbations of 5-hydroxymethylcytosine patterning in hematologic malignancies. Semin Hematol 50:61-69

73. Szulwach KE et al (2011) 5-hmC-mediated epigenetic dynamics during postnatal neurodevelopment and aging. Nat Neurosci 14:1607-1616

74. Cedar H, Bergman Y (2009) Linking DNA methylation and histone modification: patterns and paradigms. Nat Rev Genet 10:295-304

75. Hashimoto H, Vertino PM, Cheng X (2010) Molecular coupling of DNA methylation and histone methylation. Epigenomics 2:657-669

76. Wilson JR, Jing C, Walker PA, Martin SR, Howell SA, Blackburn GM, Gamblin SJ, Xiao B (2002) Crystal structure and functional analysis of the histone methyltransferase SET7/9. Cell 111:105-115

77. Keating ST, El-Osta A (2013) Transcriptional regulation by the Set7 lysine methyltransferase. Epigenetics 8:361-372

78. Pradhan S, Chin HG, Esteve PO, Jacobsen SE (2009) SET7/9 mediated methylation of non-histone proteins in mammalian cells. Epigenetics 4:383-387

79. Esteve PO, Chin HG, Benner J, Feehery GR, Samaranayake M, Horwitz GA, Jacobsen SE, Pradhan S (2009) Regulation of DNMT1 stability through SET7-mediated lysine methylation in mammalian cells. Proc Natl Acad Sci USA 106:5076-5081

80. Masatsugu T, Yamamoto K (2009) Multiple lysine methylation of PCAF by Set 9 methyltransferase. Biochem Biophys Res Commun 381:22-26

81. Yang XJ, Seto E (2007) HATs and HDACs: from structure, function and regulation to novel strategies for therapy and prevention. Oncogene 26:5310-5318

82. Dhalluin C, Carlson JE, Zeng L, He C, Aggarwal AK, Zhou MM (1999) Structure and ligand of a histone acetyltransferase bromodomain. Nature 399:491-496

83. Wang GG, Allis CD, Chi P (2007) Chromatin remodeling and cancer, part I: covalent histone modifications. Trends Mol Med 13:363-372

84. Choudhary C, Kumar C, Gnad F, Nielsen ML, Rehman M, Walther TC, Olsen JV, Mann M (2009) Lysine acetylation targets protein complexes and co-regulates major cellular functions. Science 325:834-840

85. Batchu SN, Brijmohan AS, Advani A (2016) The therapeutic hope for HDAC6 inhibitors in malignancy and chronic disease. Clin Sci (Lond) 130:987-1003
86. Chang S, McKinsey TA, Zhang CL, Richardson JA, Hill JA, Olson EN (2004) Histone deacetylases 5 and 9 govern responsiveness of the heart to a subset of stress signals and play redundant roles in heart development. Mol Cell Biol 24:8467-8476

87. McKinsey TA, Zhang CL, Olson EN (2002) MEF2: a calciumdependent regulator of cell division, differentiation and death. Trends Biochem Sci 27:40-47

88. Kuo CT, Morrisey EE, Anandappa R, Sigrist K, Lu MM, Parmacek MS, Soudais C, Leiden JM (1997) GATA4 transcription factor is required for ventral morphogenesis and heart tube formation. Genes Dev 11:1048-1060

89. Molkentin JD, Lin Q, Duncan SA, Olson EN (1997) Requirement of the transcription factor GATA4 for heart tube formation and ventral morphogenesis. Genes Dev 11:1061-1072

90. Bisping E et al (2006) Gata4 is required for maintenance of postnatal cardiac function and protection from pressure overloadinduced heart failure. Proc Natl Acad Sci USA 103:14471-14476

91. He A et al (2014) Dynamic GATA4 enhancers shape the chromatin landscape central to heart development and disease. Nat Commun 5:4907

92. Turunen MP, Yla-Herttuala S (2011) Epigenetic regulation of key vascular genes and growth factors. Cardiovasc Res 90:441-446

93. Rea S et al (2000) Regulation of chromatin structure by sitespecific histone H3 methyltransferases. Nature 406:593-599

94. Wolf SS (2009) The protein arginine methyltransferase family: an update about function, new perspectives and the physiological role in humans. Cell Mol Life Sci 66:2109-2121

95. Lee MG, Wynder C, Cooch N, Shiekhattar R (2005) An essential role for CoREST in nucleosomal histone 3 lysine 4 demethylation. Nature 437:432-435

96. Metzger E et al (2005) LSD1 demethylates repressive histone marks to promote androgen-receptor-dependent transcription. Nature 437:436-439

97. Shi Y, Lan F, Matson C, Mulligan P, Whetstine JR, Cole PA, Casero RA, Shi Y (2004) Histone demethylation mediated by the nuclear amine oxidase homolog LSD1. Cell 119:941-953

98. Tsukada Y, Fang J, Erdjument-Bromage H, Warren ME, Borchers CH, Tempst P, Zhang Y (2006) Histone demethylation by a family of JmjC domain-containing proteins. Nature 439:811-816

99. Chang B, Chen Y, Zhao Y, Bruick RK (2007) JMJD6 is a histone arginine demethylase. Science 318:444-447

100. Barski A et al (2007) High-resolution profiling of histone methylations in the human genome. Cell 129:823-837

101. Heintzman ND et al (2007) Distinct and predictive chromatin signatures of transcriptional promoters and enhancers in the human genome. Nat Genet 39:311-318

102. Kaneda $\mathrm{R}$ et al (2009) Genome-wide histone methylation profile for heart failure. Genes Cells 14:69-77

103. Patel SR, Kim D, Levitan I, Dressler GR (2007) The BRCTdomain containing protein PTIP links PAX2 to a histone H3, lysine 4 methyltransferase complex. Dev Cell 13:580-592

104. Stein AB, Goonewardena SN, Jones TA, Prusick PJ, Bazzi AA, Belyavskaya JM, McCoskey MM, Dandar RA (2015) The PTIP-associated histone methyltransferase complex prevents stress-induced maladaptive cardiac remodeling. PLoS One 10:e0127839

105. Zhang QJ, Chen HZ, Wang L, Liu DP, Hill JA, Liu ZP (2011) The histone trimethyllysine demethylase JMJD2A promotes cardiac hypertrophy in response to hypertrophic stimuli in mice. J Clin Investig 121:2447-2456

106. Oki M, Aihara H, Ito T (2007) Role of histone phosphorylation in chromatin dynamics and its implications in diseases. Subcell Biochem 41:319-336 
107. Backs $\mathbf{J}$ et al (2009) The delta isoform of CaM kinase II is required for pathological cardiac hypertrophy and remodeling after pressure overload. Proc Natl Acad Sci USA 106:2342-2347

108. Awad S et al (2015) Control of histone H3 phosphorylation by CaMKIIdelta in response to haemodynamic cardiac stress. $\mathrm{J}$ Pathol 235:606-618

109. Awad S, Kunhi M, Little GH, Bai Y, An W, Bers D, Kedes L, Poizat C (2013) Nuclear CaMKII enhances histone H3 phosphorylation and remodels chromatin during cardiac hypertrophy. Nucleic Acids Res 41:7656-7672

110. Wang H, Wang L, Erdjument-Bromage H, Vidal M, Tempst $P$, Jones RS, Zhang Y (2004) Role of histone H2A ubiquitination in Polycomb silencing. Nature 431:873-878

111. Nathan D et al (2006) Histone sumoylation is a negative regulator in Saccharomyces cerevisiae and shows dynamic interplay with positive-acting histone modifications. Genes Dev 20:966-976

112. Sakabe K, Wang Z, Hart GW (2010) $\beta-N$-acetylglucosamine (O-GlcNAc) is part of the histone code. Proc Natl Acad Sci 107:19915-19920

113. Messner S, Hottiger MO (2011) Histone ADP-ribosylation in DNA repair, replication and transcription. Trends Cell Biol 21:534-542

114. Papait R et al (2013) Genome-wide analysis of histone marks identifying an epigenetic signature of promoters and enhancers underlying cardiac hypertrophy. Proc Natl Acad Sci USA 110:20164-20169

115. Gilsbach R et al (2018) Distinct epigenetic programs regulate cardiac myocyte development and disease in the human heart in vivo. Nat Commun 9:391

116. Gaikwad AB, Sayyed SG, Lichtnekert J, Tikoo K, Anders HJ (2010) Renal failure increases cardiac histone h3 acetylation, dimethylation, and phosphorylation and the induction of cardiomyopathy-related genes in type 2 diabetes. Am J Pathol 176:1079-1083

117. Yu XY, Geng YJ, Liang JL, Lin QX, Lin SG, Zhang S, Li Y (2010) High levels of glucose induce apoptosis in cardiomyocyte via epigenetic regulation of the insulin-like growth factor receptor. Exp Cell Res 316:2903-2909

118. Yu XY et al (2012) High levels of glucose induce "metabolic memory" in cardiomyocyte via epigenetic histone H3 lysine 9 methylation. Mol Biol Rep 39:8891-8898

119. Bagul PK, Deepthi N, Sultana R, Banerjee SK (2015) Resveratrol ameliorates cardiac oxidative stress in diabetes through deacetylation of NFkB-p65 and histone 3. J Nutr Biochem 26:1298-1307

120. $\mathrm{Xu} \mathrm{Z}$ et al (2017) Inhibition of HDAC3 prevents diabetic cardiomyopathy in OVE26 mice via epigenetic regulation of DUSP5-ERK1/2 pathway. Clin Sci (Lond) 131:1841-1857

121. Bugyei-Twum A, Advani A, Advani SL, Zhang Y, Thai K, Kelly DJ, Connelly KA (2014) High glucose induces Smad activation via the transcriptional coregulator p300 and contributes to cardiac fibrosis and hypertrophy. Cardiovasc Diabetol 13:89

122. Kaur H, Chen S, Xin X, Chiu J, Khan ZA, Chakrabarti S (2006) Diabetes-induced extracellular matrix protein expression is mediated by transcription coactivator p300. Diabetes 55:3104-3111

123. Zhang L et al (2017) Sodium butyrate protects-against high fat diet-induced cardiac dysfunction and metabolic disorders in type II diabetic mice. J Cell Biochem 118:2395-2408

124. Zhao TC, Du J, Zhuang S, Liu P, Zhang LX (2013) HDAC inhibition elicits myocardial protective effect through modulation of MKK3/Akt-1. PLoS One 8:e65474

125. Sulaiman M, Matta MJ, Sunderesan NR, Gupta MP, Periasamy M, Gupta M (2010) Resveratrol, an activator of SIRT1, upregulates sarcoplasmic calcium ATPase and improves cardiac function in diabetic cardiomyopathy. Am J Physiol Heart Circ Physiol 298:H833-H843

126. Sun G, Reddy MA, Yuan H, Lanting L, Kato M, Natarajan R (2010) Epigenetic histone methylation modulates fibrotic gene expression. J Am Soc Nephrol 21:2069-2080

127. Vecellio $\mathrm{M}$ et al (2014) The histone acetylase activator pentadecylidenemalonate $1 \mathrm{~b}$ rescues proliferation and differentiation in the human cardiac mesenchymal cells of type 2 diabetic patients. Diabetes 63:2132-2147

128. Wei Y, Mizzen CA, Cook RG, Gorovsky MA, Allis CD (1998) Phosphorylation of histone $\mathrm{H} 3$ at serine 10 is correlated with chromosome condensation during mitosis and meiosis in Tetrahymena. Proc Natl Acad Sci USA 95:7480-7484

129. Gurley LR, D’Anna JA, Barham SS, Deaven LL, Tobey RA (1978) Histone phosphorylation and chromatin structure during mitosis in Chinese hamster cells. Eur J Biochem 84:1-15

130. Abdurrachim $D$ et al (2017) Diabetic db/db mice do not develop heart failure upon pressure overload: a longitudinal in vivo PET, MRI, and MRS study on cardiac metabolic, structural, and functional adaptations. Cardiovasc Res 113:1148-1160

131. Cox EJ, Marsh SA (2014) A systematic review of fetal genes as biomarkers of cardiac hypertrophy in rodent models of diabetes. PLoS One 9:e92903

132. van Heerebeek L et al (2008) Diastolic stiffness of the failing diabetic heart: importance of fibrosis, advanced glycation end products, and myocyte resting tension. Circulation 117:43-51

133. Sun J, Wang Y, Cui W, Lou Y, Sun G, Zhang D, Miao L (2017) Role of epigenetic histone modifications in diabetic kidney disease involving renal fibrosis. J Diabetes Res 2017:7242384

134. Small EM et al (2010) Myocardin-related transcription factora controls myofibroblast activation and fibrosis in response to myocardial infarction. Circ Res 107:294-304

135. Xu H, Wu X, Qin H, Tian W, Chen J, Sun L, Fang M, Xu Y (2015) Myocardin-related transcription factor A epigenetically regulates renal fibrosis in diabetic nephropathy. J Am Soc Nephrol 26:1648-1660

136. Uribarri $\mathrm{J}$ et al (2010) Advanced glycation end products in foods and a practical guide to their reduction in the diet. J Am Diet Assoc 110(911-16):e12

137. Thomas MC et al (2015) Relationship between levels of advanced glycation end products and their soluble receptor and adverse outcomes in adults with type 2 diabetes. Diabetes Care 38:1891-1897

138. Pashikanti S, Boissonneault GA, Cervantes-Laurean D (2011) Ex vivo detection of histone $\mathrm{H} 1$ modified with advanced glycation end products. Free Radic Biol Med 50:1410-1416

139. Gugliucci A, Bendayan M (1995) Histones from diabetic rats contain increased levels of advanced glycation end products. Biochem Biophys Res Commun 212:56-62

140. Li Y, Reddy MA, Miao F, Shanmugam N, Yee JK, Hawkins D, Ren B, Natarajan R (2008) Role of the histone H3 lysine 4 methyltransferase, SET7/9, in the regulation of NF-kappaB-dependent inflammatory genes. Relevance to diabetes and inflammation. J Biol Chem 283:26771-26781

141. El-Osta A, Brasacchio D, Yao D, Pocai A, Jones PL, Roeder RG, Cooper ME, Brownlee M (2008) Transient high glucose causes persistent epigenetic changes and altered gene expression during subsequent normoglycemia. J Exp Med 205:2409-2417

142. Zhong Q, Kowluru RA (2011) Epigenetic changes in mitochondrial superoxide dismutase in the retina and the development of diabetic retinopathy. Diabetes 60:1304-1313

143. Advani A et al (2009) Expression, localization, and function of the thioredoxin system in diabetic nephropathy. J Am Soc Nephrol 20:730-741 
144. Connelly KA et al (2014) Impaired cardiac anti-oxidant activity in diabetes: human and correlative experimental studies. Acta Diabetol 51:771-782

145. Siddiqi FS et al (2016) The histone methyltransferase enzyme enhancer of Zeste homolog 2 protects against podocyte oxidative stress and renal injury in diabetes. J Am Soc Nephrol 27:2021-2034

146. Perrone L, Devi TS, Hosoya K, Terasaki T, Singh LP (2009) Thioredoxin interacting protein (TXNIP) induces inflammation through chromatin modification in retinal capillary endothelial cells under diabetic conditions. J Cell Physiol 221:262-272

147. Zhou S et al (2011) Repression of P66Shc expression by SIRT1 contributes to the prevention of hyperglycemia-induced endothelial dysfunction. Circ Res 109:639-648

148. Costantino $S$ et al (2017) Impact of glycemic variability on chromatin remodeling, oxidative stress, and endothelial dysfunction in patients with type 2 diabetes and with target HbA1c levels. Diabetes 66:2472-2482

149. Liu M et al (2017) Sirt6 deficiency exacerbates podocyte injury and proteinuria through targeting Notch signaling. Nat Commun 8:413

150. Gallagher KA et al (2015) Epigenetic changes in bone marrow progenitor cells influence the inflammatory phenotype and alter wound healing in type 2 diabetes. Diabetes 64:1420-1430

151. Villeneuve LM, Reddy MA, Lanting LL, Wang M, Meng L, Natarajan R (2008) Epigenetic histone H3 lysine 9 methylation in metabolic memory and inflammatory phenotype of vascular smooth muscle cells in diabetes. Proc Natl Acad Sci USA 105:9047-9052

152. Sharma S, Kriebel J, Grallert H (2017) Epigenetic regulation of glucose metabolism. Curr Opin Clin Nutr Metab Care 20:266-271

153. Fukushima A, Lopaschuk GD (2016) Acetylation control of cardiac fatty acid beta-oxidation and energy metabolism in obesity, diabetes, and heart failure. Biochim Biophys Acta 1862:2211-2220

154. Taylor EM, Jones AD, Henagan TM (2014) A review of mitochondrial-derived fatty acids in epigenetic regulation of obesity and type 2 diabetes. J Nutr Health Food Sci 2:1-4

155. Zhong Q, Kowluru RA (2013) Regulation of matrix metalloproteinase- 9 by epigenetic modifications and the development of diabetic retinopathy. Diabetes 62:2559-2568

156. Rugg-Gunn PJ, Cox BJ, Ralston A, Rossant J (2010) Distinct histone modifications in stem cell lines and tissue lineages from the early mouse embryo. Proc Natl Acad Sci USA 107:10783-10790

157. Majumder $\mathrm{S}$ et al (2018) Shifts in podocyte histone H3K27me3 regulate mouse and human glomerular disease. J Clin Investig 128:483-499

158. Iwamoto M, Friedman EJ, Sandhu P, Agrawal NG, Rubin EH, Wagner JA (2013) Clinical pharmacology profile of vorinostat, a histone deacetylase inhibitor. Cancer Chemother Pharmacol 72:493-508

159. Richon VM, Garcia-Vargas J, Hardwick JS (2009) Development of vorinostat: current applications and future perspectives for cancer therapy. Cancer Lett 280:201-210

160. Zhou $\mathrm{N}$ et al (2008) Discovery of $N$-(2-aminophenyl)-4-[(4-pyridin-3-ylpyrimidin-2-ylamino)methyl]benzamide (MGCD0103), an orally active histone deacetylase inhibitor. J Med Chem 51:4072-4075

161. Khan N et al (2008) Determination of the class and isoform selectivity of small-molecule histone deacetylase inhibitors. Biochem J 409:581-589
162. Pidugu VR, Yarla NS, Bishayee A, Kalle AM, Satya AK (2017) Novel histone deacetylase 8-selective inhibitor 1,3,4-oxadiazolealanine hybrid induces apoptosis in breast cancer cells. Apoptosis 22:1394-1403

163. Mould DP et al (2017) Development of (4-cyanophenyl)glycine derivatives as reversible inhibitors of lysine specific demethylase 1. J Med Chem 60:7984-7999

164. Mould DP, Bremberg U, Jordan AM, Geitmann M, McGonagle AE, Somervaille TCP, Spencer GJ, Ogilvie DJ (2017) Development and evaluation of 4-(pyrrolidin-3-yl)benzonitrile derivatives as inhibitors of lysine specific demethylase 1. Bioorg Med Chem Lett 27:4755-4759

165. Kruidenier L et al (2012) A selective jumonji H3K27 demethylase inhibitor modulates the proinflammatory macrophage response. Nature 488:404-408

166. Sterner DE, Berger SL (2000) Acetylation of histones and transcription-related factors. Microbiol Mol Biol Rev 64:435-459

167. Roth SY, Denu JM, Allis CD (2001) Histone acetyltransferases. Annu Rev Biochem 70:81-120

168. Seto E, Yoshida M (2014) Erasers of histone acetylation: the histone deacetylase enzymes. Cold Spring Harb Perspect Biol 6:a018713

169. Hyun K, Jeon J, Park K, Kim J (2017) Writing, erasing and reading histone lysine methylations. Exp Mol Med 49:e324

170. Tsukada Y, Ishitani T, Nakayama KI (2010) KDM7 is a dual demethylase for histone H3 Lys 9 and Lys 27 and functions in brain development. Genes Dev 24:432-437

171. Greer EL, Shi Y (2012) Histone methylation: a dynamic mark in health, disease and inheritance. Nat Rev Genet 13:343-357

172. Ito $\mathrm{E}$ et al (2017) Histone modification is correlated with reverse left ventricular remodeling in nonischemic dilated cardiomyopathy. Ann Thorac Surg 104:1531-1539

173. Papait $R$ et al (2017) Histone methyltransferase G9a is required for cardiomyocyte homeostasis and hypertrophy. Circulation 136:1233-1246

174. Han $P$ et al (2016) Epigenetic response to environmental stress: assembly of BRG1-G9a/GLP-DNMT3 repressive chromatin complex on Myh6 promoter in pathologically stressed hearts. Biochim Biophys Acta 1863:1772-1781

175. Zakharova L, Nural-Guvener H, Feehery L, Popovic-Sljukic S, Gaballa MA (2015) Transplantation of epigenetically modified adult cardiac c-kit+ cells retards remodeling and improves cardiac function in ischemic heart failure model. Stem Cells Transl Med 4:1086-1096

176. Ono $\mathrm{T}$ et al (2017) The histone 3 lysine 9 methyltransferase inhibitor chaetocin improves prognosis in a rat model of high salt diet-induced heart failure. Sci Rep 7:39752

177. Pedram A, Razandi M, Narayanan R, Dalton JT, McKinsey TA, Levin ER (2013) Estrogen regulates histone deacetylases to prevent cardiac hypertrophy. Mol Biol Cell 24:3805-3818

178. Peng C, Luo X, Li S, Sun H (2017) Phenylephrine-induced cardiac hypertrophy is attenuated by a histone acetylase inhibitor anacardic acid in mice. Mol BioSyst 13:714-724

179. Thienpont B et al (2017) The H3K9 dimethyltransferases EHMT1/2 protect against pathological cardiac hypertrophy. J Clin Investig 127:335-348

180. Pharaon LF, El-Orabi NF, Kunhi M, Al Yacoub N, Awad SM, Poizat C (2017) Rosiglitazone promotes cardiac hypertrophy and alters chromatin remodeling in isolated cardiomyocytes. Toxicol Lett 280:151-158 